\title{
STRATEGIC REBELS: A SPATIAL ECONOMETRIC APPROACH TO REBEL FIGHTING DURATIONS IN CIVIL WARS
}

\author{
NILS W. METTERNICH AND JULIAN WUCHERPFENNIG
}

\begin{abstract}
Recent research on multi-actor civil wars highlights that rebel organizations condition their conflict behavior on that of other rebel organizations, with competition and free-riding constituting the core theoretical mechanisms. We provide a new actorcentric approach to explicitly model strategic interdependence in multi-actor civil wars. We argue that rebel organizations have incentives to remain mobilized until the end of a conflict to maintain their power to negotiate, power to spoil, power to enforce, and power to protect. This induces strategic complements that dominate duration dynamics in multiactor conflicts. Based on a network game theoretic model, we derive a spatial econometric framework that allows for a direct test of strategic interdependence. We find that the estimated duration interdependence is positive, but partially offset in secessionist conflicts where the public goods nature of the incompatibility also induces strategic substitution effects.
\end{abstract}

\section{INTRODUCTION}

Historically about half of all civil conflicts involve multiple rebel organizations fighting the government (Gleditsch et al., 2002; Walter, 2019). These multi-actor settings are consistently linked to long durations (Cunningham, 2006; Cunningham, Gleditsch and Salehyan, 2009), as well as greater human suffering (Wood and Kathman, 2015), as exemplified by the ongoing Syrian civil war (Gade, Hafez and Gabbay, 2019).

A key premise in theoretical approaches to such multi-actor conflicts is that the behavior of rebel organizations is inherently strategic and interdependent (Cunningham, 2006, 2011;

Date: March 25, 2020 Version 2.01.

We are indebted to Jude Hays for initial hints and inspiration on the setup of the statistical model. We thank Lars-Erik Cederman, Kristian Skrede Gleditsch, James Morrow, Andrea Ruggeri, Idean Salehyan, Camber Warren, and Steffen Weiss for comments and discussion. All remaining errors are ours alone. Nils W. Metternich acknowledges support from the Economic and Social Research Council (ES/L011506/1) and the Gerda Henkel Stiftung (AZ 07/KF/13). Replication material is available at https://dataverse.harvard.edu/dataverse/internationalinteractions. Please contact the authors for all questions regarding replication material. 
Akcinaroglu, 2012; Christia, 2012; Driscoll, 2012; Findley and Rudloff, 2012; Fjelde and Nilsson, 2012; Nygård and Weintraub, 2015; Wood and Kathman, 2015; Fjelde and Nilsson, 2018; Quinn, Joshi and Melander, 2019). Rebel organizations condition their choice to fight, use one-sided violence, or sign peace-agreements not only on government behavior, but also on the (expected) behavior of other rebel organizations. This interdependence between actors is not only prominent in the civil war literature, but also extends to other forms of political violence, such as terrorism (Bloom, 2005; Phillips, 2014; Nemeth, 2014; Conrad and Greene, 2015).

Despite this growing literature on multi-actor conflicts, there is less consensus on how to theoretically and empirically model strategic relations between multiple actors, and especially how to draw empirical inferences in the context of interdependent actors. Recent network approaches are most explicit and address interdependencies between armed actors head-on (Metternich et al., 2013; König et al., 2017; Gade, Hafez and Gabbay, 2019). We seek to built upon this work by providing a theoretical and empirical model of how multi-actor conflicts induce strategic behavior, focusing on the fighting durations of armed actors.

By focusing on strategic interdependencies of fighting durations, we address an important limitation in the study of civil wars. While the onset, escalation, and outcome of civil wars have seen efforts to model the interdependency between rebel organizations explicitly, scholarly contributions to study of fighting durations have tended to model interdependency only implicitly. Explicit approaches attempt to model dependency of actors directly by using network analytic or spatial statistical approaches to infer patterns of interdependency by fully endogenizing interdependent outcomes, while implicit approaches focus on variables that proxy the degree to which interdependency impacts on actors' decisions. Indeed, most scholars analyzing fighting durations in civil wars follow the implicit approach suggested by the seminal work of Cunningham (2006), who includes the number of armed actors in a conflict as a covariate intended to capture strategic dependence that arises from veto player dynamics. 
Our focus on fighting durations allows us to make two contributions. First, we present a theoretical framework that highlights the incentives rebel organizations face to remain mobilized until the end of a conflict. Second, we propose a spatial econometric estimation framework that allows us to directly test the empirical implications of theories that assume strategic interactions between rebel organizations.

Our theoretical framework highlights rebel organizations' incentives to remain mobilized until the end of the conflict. These incentives arise because mobilized rebel organizations can maintain their ability to enter negotiations ((i) power to negotiate) or influence their outcome from the outside ((ii) power to spoil). Even groups that are granted or offered government concessions before the end of a conflict have incentives to remain mobilized to circumvent commitment problems ((iii) power to enforce) and protect their supporters from the government of other rebel organizations while the conflict is still ongoing ((iv) power to protect). Together, this implies that fighting durations in multi-actor conflicts become strategic complements. However, where conflict incompatibilities entail a strong public goods aspect or conflict parties can enter binding agreements, strategic substitution effects between rebel organizations can offset strategic complementarity. We argue that secessionist conflicts are especially prone to observe strategic substitution effects, where all rebel organizations can benefit from a potential new and independent state.

Our statistical approach accounts for endogenous rebel fighting durations due to simultaneity arising from interdependent decision-making. We develop a statistical model that not only 'controls' for duration of other rebel organizations, but fully endogenizes rebel organizations' fighting durations, even when these decisions are strategically interdependent across actors. Our spatial econometric approach allows us examine the extent of strategic interaction between rebel organizations. We find evidence for the argument that rebel organizations generally engage in competitive behavior, attempting to outperform one another by means of longer fighting. In line with the literature, we refer to such positive interdependence as strategic complementarity in outcomes (Franzese and Hays, 2008). However, in separatist conflicts, where public goods considerations can be expected to be more pronounced, we find 
that competition dynamics are partially offset by negative interdependence through incentives to free-ride (strategic substitution). Finally, we show that strategic interaction is not merely a statistical nuisance and that taking full account of it improves our ability to explain and predict rebel fighting durations.

\section{Conflict Duration and Multiple Actors}

A burgeoning literature has addressed the interdependency of armed actors in conflicts. This scholarship on multiple actor conflicts generally falls into two strands: (1) studies that see rebel fighting as strategic complements (rebel competition and fragmentation), and (2) those that view it as strategic substitutes (rebel cooperation and alliances). While Cunningham, Gleditsch and Salehyan $(2009,572)$ already suggested that rebels at times fight each other more often than the government, this idea is investigated in more detail by Fjelde and Nilsson (2012) who argue that competition over material and political spoils triggers inter-rebel violence. Similarly, focusing on fragmentation in self-determination disputes, Cunningham, Bakke and Seymour (2012) highlight that faction leaders also seek control of private and club goods, which drives competition.

However, as pointed out by these authors, fighting the government frequently entails not only public good, but also private good aspects (Fjelde and Nilsson, 2012; Cunningham, Bakke and Seymour, 2012). Bapat and Bond (2012) identify specific conditions under which rebel organizations overcome commitment problems and form alliances. Similarly, Christia (2012) analyses how power distributions within alliances lead to their fragmentation and continued fighting when small power-shifts can induce changes in the order of power relationships. In a more optimistic take on alliances within movements, Bakke, Cunningham and Seymour (2012) argue that increased institutionalization increases cohesion between groups by providing non-violent mechanisms that mitigate conflict among groups. Similarly, Akcinaroglu (2012) suggests that credible alliances with strong ties increase the chances of 
TABLE 1. Ideal types of analyzing fighting durations and the link between theory and empirical model. Gray dots pertain to the government, black dots to rebel organizations. Arrows describe assumed strategic interdependence between actors. In a purely actor based approach, the utility of continuing to fight is simply a function of actor specific characteristics $(X)$. A dyadic approach focuses on the interaction between the a rebel organization and a government, where the decision of a rebel organization to fight depends on dyadic features $Z$ and actor characteristics $X$. In a constellation approach, the rebel-government relationship is conditioned by constellation features $K$ (e.g. number of actors), but rebels do not strategically condition their behavior on other rebel-government dyads. In a strategic approach, all rebels condition their behavior $Y$ on all other rebels' observed and expected behavior $Y$ they are connected to through $W$.

\begin{tabular}{|c|c|c|c|}
\hline Type & Representation & Theoretical Utility & Empirical Estimation \\
\hline Actor & • & $U_{i}(X)$ & $y=X \beta+\epsilon$ \\
\hline Dyadic & & $U_{i}(X, Z)$ & $y=X \beta+Z \zeta+\epsilon$ \\
\hline Constellation & & $U_{i}(X, Z, K)$ & $y=X \beta+Z \zeta+K \kappa+\epsilon$ \\
\hline Strategic & & $U_{i}\left(X, Z, Y_{j}, W\right)$ & $y=X \beta+Z \zeta+K \kappa+\rho W Y+\epsilon$ \\
\hline
\end{tabular}

rebel victories. Applying a computational perspective, Findley and Rudloff (2012) demonstrate that fragmentation of rebel organizations can actually decrease fighting durations, thus contrasting to insights from Cunningham (2006).

It is apparent from this discussion that the theoretical literature readily acknowledges the importance of strategic interaction between rebel organizations (cf. Cunningham, 2006; Cunningham, Gleditsch and Salehyan, 2009; Fjelde and Nilsson, 2012; Cunningham, Bakke and Seymour, 2012; Cunningham, 2013). Most prominent theoretical arguments, e.g. the veto player approach Cunningham (2006), are fundamentally strategic approaches in which actors condition their behavior on the observed and expected behavior of all other actors. In Table 1, strategic theories condition the choice of rebel organizations not only on actor and 
dyad specific characteristics, but on the expected and observed behavior of all other dyads in a conflict.

However, while the empirical study of civil war onset, escalation, and termination has made great strides to address the strategic dependency explicitly, ${ }^{1}$ observational studies of fighting durations tend to use implicit measures of dependency. This is because most studies focusing on fighting durations employ conventional statistical tools that assume rebel organizations to be de facto independent. More precisely, conventional duration estimators (e.g. parametric duration models) assume that the stochastic error terms are sampled conditionally independent (iid assumption). While almost all fighting duration studies attempt account for strategic interdependence by including the number of rebel organizations involved in a conflict (the constellation approach in Table 1), we argue that this does not capture the theoretically implied data-generating process and might even lead to incorrect parameter estimates and inference. ${ }^{2}$ This problem arises because strategic interaction squarely implies that actions (outcomes) by other actors (or expectations thereof) need to appear as endogenous right-hand side variables (Franzese and Hays, 2008; Hays and Kachi, 2015; Hays, 2009). By contrast, approaches that focus on exogenous structural constellations omit these actions taken by other actors altogether. Based on these considerations, we aim to reframe the debate. Rather than examining the effects of particular constellations, we ask how the decision of one rebel organization to endure fighting affects that of other organizations, and-importantly-vice-versa.

\section{The Logic of Enduring fighting: A theoretical Model of}

\footnotetext{
${ }^{1}$ Increasing awareness to these interdependencies have been addressed not only by network approaches (e.g. Metternich et al., 2013; König et al., 2017; Gade, Hafez and Gabbay, 2019), but also random effect models (see Cunningham and Sawyer, 2017)

${ }^{2}$ Note that because coefficients will be biased, clustering standard errors will not solve this problem, i.e., incorrect inference will prevail. See also Poast (2010).
} 


\section{Fighting Durations}

When should a rebel organizations lay down their weapons? This question is at the heart of determining the fighting duration of rebel organizations. We argue that in multi-actor conflicts there are clear incentives to match the fighting durations of other rebel organizations and remain mobilized until the end of a conflict. We argue that these incentives make multi-actor conflicts particularly long and add to the already established bargaining issues (Cunningham, 2006; Gallop, 2017) in these types of conflicts. We argue that incentives to match fighting durations can be attributed to four mechanisms, all of which maximize a rebel organization's ability to shape the post-conflict aftermath. These are the: (i) power to negotiate, (ii) power to spoil, (iii) power to enforce, and (iv) power to protect.

Power to negotiate. The simplest path to shaping the institutions and divisions of spoils after the conflict has ended is to sit at the bargaining table when peace negotiations take place. A key to taking part in these negotiations is to be mobilized, exert violence, and constitute a potent threat to the government (Clayton, 2013; Thomas, 2014). Alternatively, if the rebels manage to defeat the government, similar negotiations typically take place among those organizations that remained active until the end of the conflict, i.e. those that were able to claim victory.

Power to spoil. However, in many conflicts, a subset of rebel organizations remains precluded from peace negotiations due to perceived weakness or other ideological issues. For such groups the incentives to stay mobilized as long as possible is to undermine negotiations from the outside through their ability to spoil negotiations in the hope of sitting at the bargaining table at a later time (Stedman, 1997; Findley and Young, 2015).

Power to enforce. Rebel organizations receive offers by the government or competing rebel organizations to cease their activity. However, accepting such cooptation is risky. Indeed, there are incentives for, e.g., the government to renege on offers during the conflict and before these 'contracts' are enshrined in post-conflict institutions (Walter, 1999). Therefore 
rebel organizations have incentives to remain mobilized at low levels of fighting to ensure that they can enforce any pre-conflict termination agreement (Fearon, 2004).

Power to protect. Finally, as conflict generates grievances, including desire for revenge (Petersen, 2002), there are incentives for rebel organizations to remain mobilized in order to protect their constituencies in times of armed conflict. Thus, even if a rebel organization ceases their offensive activities, there are incentives to remain mobilized, at least until the overall fighting has stopped, and protect their respective followers or constituencies from potential reprisals by the government or rivaling rebel organizations (Wucherpfennig et al., 2012).

These mechanism highlight that long durations not necessarily imply high intensity fighting. ${ }^{3}$ In fact, there might be environments that are more conducive to enable rebel organizations' long survival times at low intensity levels (e.g. weak governments).

Fighting durations as strategic complements. We now turn to formalizing these conjectures. The incentives to stay mobilized until the end of conflict imply that rebel organizations will strategically condition their choice to lay down arms on the choices of all other active rebel organizations. In fact, it is reasonable to assume that when rebel organizations enter a conflict they already condition their expectation about the duration of fighting on the fighting duration of all other actors and adapt their fighting strategies accordingly. This dynamic of attempting stay mobilized as long as all other rebel organization leads to strategic complements of fighting.

We draw on recent work analyzing the provision of local public goods (Bramoullé and Kranton, 2007; Galeotti et al., 2010; Bramoullé, Kranton and D'Amours, 2014; Siegel, 2009; Metternich et al., 2013; Steinwand, 2011). Using the analytic framework provided by Bramoullé, Kranton and D'Amours (2014), we formalize these considerations in a simple

\footnotetext{
${ }^{3}$ See 'power to resist' in Cunningham, Gleditsch and Salehyan (2009) and Conrad et al. (2019).
} 
model that assumes $N$ rebel organizations in conflict with the government. Each organization $i$ remains active for certain amount of time $y_{i} \geq 0$ to retain their (i) power to negotiate, (ii) power to spoil, (iii) power to enforce, and (iv) power to protect.

In a multi-actor setting it is possible to take a network perspective to describe how rebel organization $i$ 's fighting duration impacts on other organizations $j$ 's fighting duration and therefore their (i) power to negotiate, (ii) power to spoil, (iii) power to enforce, and (iv) power to protect. Whether $i$ is impacted by $j$ 's decision to continue fighting depends on whether they are connected in an $N \times N$ matrix $\mathbf{W}$, where $w_{i j}$ is the element in the $i$ th row and $j$ th column. Thus, if $w_{i j}=1, i$ 's (i) power to negotiate, (ii) power to spoil, (iii) power to enforce, and (iv) power to protect are directly impacted by $j$ 's fighting duration. Given that fighting is costly, the extent to which $i$ experiences negative externalities from $j$ 's fighting duration depends on a parameter $\gamma \in[0,1)$ which denotes the complementarity between $i$ 's fighting duration and other rebels in the conflict. The greater $\gamma$ the less $i$ benefits from $j$ 's fighting duration in regard to $i$ 's a) power to negotiate, b) power to spoil, c) power to enforce, and d) power to protect. The utility of an individual rebel organization can therefore be written as:

$$
U_{i}\left(y_{i}, \mathbf{y}_{\mathbf{j}}, \gamma, \mathbf{W}\right)=b_{i}\left(y_{i}-\gamma \sum_{j} w_{i j} y_{j}\right)-c_{i} y_{i}
$$

Here, $b_{i}$ is a differentiable benefit function that is strictly increasing and concave in $y_{i}$, i.e., $b(0)=0, b^{\prime}=0$ and $b^{\prime \prime}<0$. We also assume that each organization incurs some marginal $\operatorname{cost} c_{i}>0$ per unit of fighting duration, such that $b^{\prime}(0)>c_{i}>b^{\prime}(+\infty)$.

Assuming that each rebel organization $i$ has a fighting duration $\bar{y}_{i}$ that it is willing to sustain fighting the government alone (i.e. idiosyncratic fighting duration), the best response of this model implies that $y_{i}^{*}$ increases as the efforts of other rebel organizations increase. This gives rise to competitive dynamics between rebel organizations.

$$
y_{i}^{*}=\bar{y}_{i}+\gamma \sum_{j} w_{i j} y_{j}
$$


From this best response, we can derive our main empirical expectation of positive interdependence. Thus, the longer rebel organization $j$ fights the longer rebel organization $i$ fights to retain their (i) power to negotiate, (ii) power to spoil, (iii) power to enforce, and (iv) power to protect.

Alternative Argument: Fighting durations as strategic substitutes. Our four mechanisms that drive strategic complementarity assume that rebel organizations are in an environment that impedes binding agreements and/or is characterized by low levels of trust. Actors with different interest are therefore incentivized to stay mobilized until the end of the conflict. However, this also implies that if actors have completely aligned preferences about generating particular public goods after the fighting stops or have a higher capacity to enter binding agreements, strategic substitution effects should offset or counteract complementarity dynamics.

Indeed, there are good arguments that particular conflicts, in which all actors share the same interests and trust other rebel organization to implement their preferred post-conflict institutions and division of spoils, can lead to actors deciding to lay down their arms before the conflict has ended. For example, in secessionist conflicts, rebel organizations share the objective of a newly independent state, which has strong characteristics of a public good. In other words, some conflict incompatibilities, such as gaining independence, are to a large extent non-excludable and non-rivalrous (cf. Olson, 1965; Cunningham, Bakke and Seymour, 2012; Metternich et al., 2013).

The non-excludability and non-rivalry of public goods give rise to free-riding and collective action problems (Olson, 1965). Such problems are well identified in civil wars, including that of individual-level rebel recruitment (Lichbach, 1995; Gates, 2002; Wood, 2003), but they also exist between rebel organizations. For example, secessionist victories not only benefit the main rebel organizations, but also all other anti-government organizations (cf. Schnytzer, 1994). As Collier (2000, 98) puts it: "Justice, revenge, and relief from grievance are "public goods" and so are subject to free-riding." 
Again we can take a network perspective to formalize these dynamics. Substitution effects arise because $i$ enjoys positive externalities from $j$ 's (i) power to negotiate, (ii) power to spoil, (iii) power to enforce, or (iv) power to protect. For example, this is the case if $j$ 's power to negotiate will lead to an outcome that benefits $i$. The degree to which $i$ benefits from $j$ 's fighting duration depends on a parameter $\delta \in[0,1)$ which denotes the extent of substitutability between $i$ 's fighting duration and those of her neighbors. The utility of an individual rebel organization can therefore be written as:

$$
U_{i}\left(y_{i}, \mathbf{y}_{\mathbf{j}}, \delta, \mathbf{W}\right)=b_{i}\left(y_{i}+\delta \sum_{j} w_{i j} y_{j}\right)-c_{i} y_{i}
$$

Following Bramoullé, Kranton and D'Amours (2014), the best response function for every rebel organization $i$ in this game is: ${ }^{4}$

$$
\begin{array}{ll}
y_{i}^{*}=\bar{y}_{i}-\delta \sum_{j} w_{i j} y_{j} & \text { if } \delta \sum_{j} w_{i j} y_{j}<\bar{y}_{i} \\
y_{i}^{*}=0 & \text { if } \delta \sum_{j} w_{i j} y_{j} \geq \bar{y}_{i}
\end{array}
$$

The best response given in Eq. 4 follows the simple intuition that rebel organization $i$ will endure fighting $y_{i}^{*}$ that ensures that its willingness of sustained fighting $\bar{y}_{i}$ is generated given its neighbors' fighting durations. If its neighbors underprovide, $i$ makes up the difference, and no contribution otherwise. Eq. 4 highlights that in the absence of strategic independence $(\delta=0$ in Eq. 4), individual fighting durations are solely dependent on the characteristics of a given rebel organization. However, if we allow rebel organizations to benefit from the fighting durations of other organizations (implied by $\delta>0$ in Eq. 3), rebel organizations can achieve their optimal fighting duration $\bar{y}_{i}$ by free-riding on others' fighting efforts.

\footnotetext{
${ }^{4} \bar{y}_{i}$ is obtained from the first order condition by equating marginal benefits with marginal costs, i.e.: $\frac{\partial U_{i}}{\partial y_{i}}=b^{\prime}(y)-c_{i}=0$.
} 


\section{Towards an Empirical Model of Strategic Duration Interdependence}

In this section we combine the logics of strategic complementarity and strategic substitution so as to allow for an empirical model. As previously pointed out, Cunningham, Bakke and Seymour (2012) argue that complementarity and substitution logics can operate at the same time. Hence, we provide an extended model that can account for both fighting durations as substitutes and complements, which will allow us to derive an estimation approach to assess whether strategic complements or substitutes are on average more dominant in fighting duration dynamics. Accounting for both strategic complements or substitutes, we can combine Equation 1 and 3:

$$
U_{i}\left(y_{i}, \mathbf{y}_{\mathbf{j}}, \delta, \gamma, \mathbf{W}\right)=b_{i}\left(y_{i}+\delta \sum_{j} w_{i j} y_{j}-\gamma \sum_{j} w_{i j} y_{j}\right)-c_{i} y_{i}
$$

In line with Cunningham, Bakke and Seymour (2012), the full model highlights that incentives for free-riding and competition can exist simultaneously, precisely because the terms for $\delta$ and $\gamma$ differ merely in sign, thus potentially offsetting each other. Hence, only the net effect of the two can be observed, and given our framework we can observe whether the free-riding or competition logic prevails. Thus, we simplify as follows:

$$
U_{i}\left(y_{i}, \mathbf{y}_{\mathbf{j}}, \rho, \mathbf{W}\right)=b_{i}\left(y_{i}+\rho \sum_{j} w_{i j} y_{j}\right)-c_{i} y_{i}
$$

where $\rho=\delta-\gamma$. Note that $\rho \in(-1,1)$. Moreover, the best response function for every rebel organization $i$ is: ${ }^{5}$

$$
y_{i}^{*}=\bar{y}_{i}+\rho \sum_{j} w_{i j} y_{j}
$$

This best response implies that depending on the whether the public goods or the rivalry mechanism prevails, rebel organizations will have incentives to decrease or increase their

\footnotetext{
${ }^{5}$ Note that pure strategy equilibrium hinges on an exogenous upper bound on $y_{i}$ when $\rho<0$. Empirically, this upper bound exists if finite endowments or resources exist.
} 
individual contribution. Substantively, if $\rho>0$ in Eq. 7, competitive dynamics dominate, if $\rho<0$ free-riding dominates. To illustrate and summarize the substantive interpretation, in Figure 1 we visualize some comparative statics for different values of $\rho$.

We consider a scenario with four rebel organizations, $i=\{1,2,3,4\}$. Optimal (idiosyncratic) fighting durations (that each rebel organization were to inflict upon the government if it was alone in the conflict) are set to $\bar{y}_{i}=\{10,20,30\}$ for $i=\{1,2,3\}$. The $\mathrm{x}$-axis represents organization 4's idiosyncratic fighting durations, while the y-axis denotes the optimal (equilibrium) effect $^{6}$ for each organization. The left panel shows a baseline scenario and highlights that in the absence interdependence $(\rho=0)$, the equilibrium fighting durations of all players remains identical to their idiosyncratic fighting durations. The middle panel considers the case of positive interdependence $(\rho=.1)$, i.e. when fighting efforts are strategic complements. As rebel organization 4's $\bar{y}_{4}$ increases from 10 to 30, the other organizations' (optimal) fighting efforts increase as well. The right panel highlights the reverse effect $(\rho=-.1)$, and demonstrates decreasing incentives to contribute as $\bar{y}_{4}$ increases (i.e. free-riding).
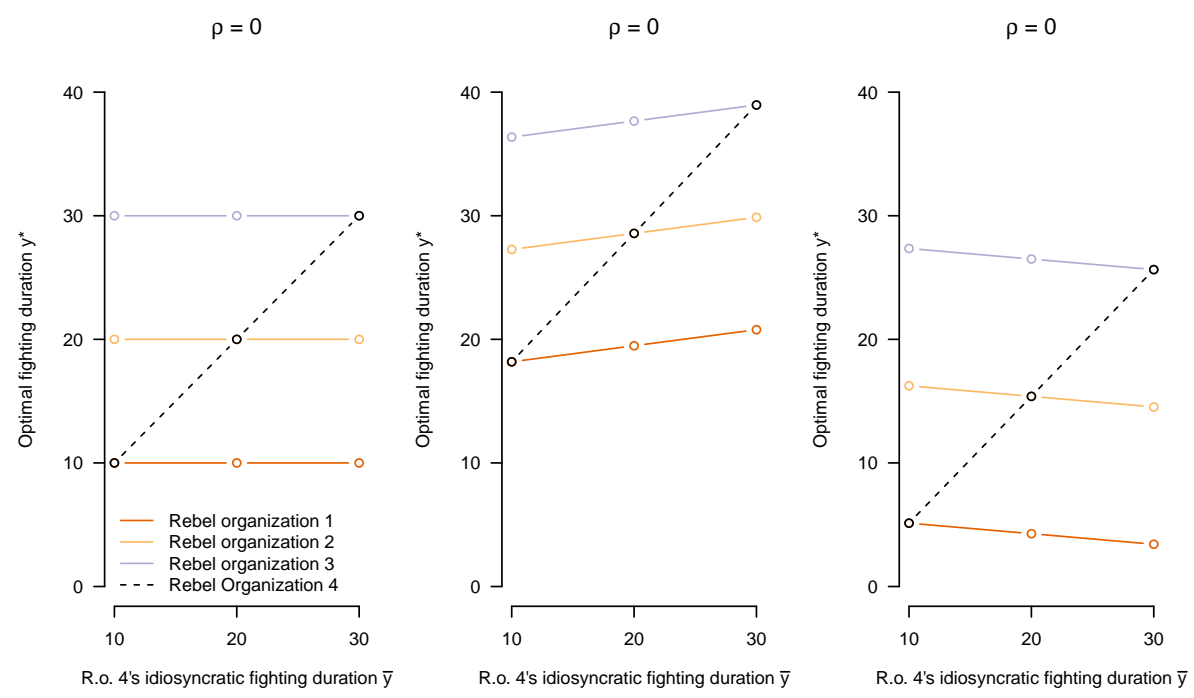

FiguRE 1. Best response functions of three rebel organizations to responding to increasing efforts of a fourth rebel organization.

${ }^{6}$ These are calculated as $y_{i}^{*}=\frac{1}{1-\rho \sum_{j} y_{j}} \bar{y}_{i}$. 


\section{Spatial Econometric Approach}

In this section we draw on spatial econometrics and present an empirical strategy to estimate best responses as given in equation 7 . Our theoretical considerations imply that rebel actions are partly determined through mutual interdependence where each rebel organization considers the (expected) behavior of her neighbors, and vice versa. This implies strategic interdependence and consequently, the outcome of interest - fighting durationssimultaneously represents an explanatory factor. This induces a particular endogeneity problem (bias) which cannot be accommodated by standard estimation techniques, or by simply introducing exogenous spatial lags as a conventional explanatory variable.

As highlighted above, $y$ appears on both sides of the equation, which implies an endogeneity problem due to simultaneity. In the absence of an adequate estimator, this leads to a violation of the statistical assumption of independent units and uncorrelated error terms. A prominent solution to this problem is the estimation of spatial econometric models (Franzese and Hays, 2008). This class of estimators is designed to account for, and estimate the degree of, interdependence between units, and has only recently reached the mainstream of political science (Ward and Gleditsch, 2002; Cho, 2003; Simmons and Elkins, 2004; Beck, Gleditsch and Beardsley, 2006; Gleditsch and Ward, 2006; Franzese and Hays, 2007). In the context of civil war, spatial econometrics have been used to assess the economic effect of civil wars on neighboring countries (Murdoch and Sandler, 2004), the effect refugees have on civil war onset (Salehyan, 2007), clustering of civil wars (Buhaug and Gleditsch, 2008), and transnational factors influencing civil war onset (Gleditsch, 2007). Spatial interdependence is commonly equated with aspects of geography, such as proximity or contiguity. However, as Beck, Gleditsch and Beardsley (2006) and Franzese and Hays (2008) elaborate, in principle there is no reason to restrict the operationalization of interdependence to physical distance and we use spatial econometrics, spatial duration analysis in particular, to model the strategic interdependence between rebel organizations within multi-actor conflicts. 
Interdependent durations. We are interested in the fighting durations of rebel organizations and hence our estimation approach is based on event history models. Models of interdependent duration are rare in political science and in the context of armed conflict we are only aware of one study focusing on duration dependence within WWI (Hays, Schilling and Boehmke, 2015). Applications from other subfields include Quiroz Flores (2008) estimating the tenure of chief executive officers and the median duration of their ministers as interdependent using a seemingly unrelated regression (SUR) estimator. Darmofal (2009) uses a spatial-error approach to estimate issue position taking on NAFTA in the U.S. Congress. Our approach builds on spatial duration estimators developed by Hays and Kachi (2015) and Hays (2009). In our context, an additional challenge arises because fighting durations of rebel organizations do not necessarily have the same start date. They are frequently nonaligned over the length of the conflict and as a consequence the set of strategically dependent rebel organizations varies across time. Our estimation framework explicitly addresses these dynamics.

Consider a standard parametric event history model, such as a Weibull or log-normal event history model. This can be written in accelerated failure time (AFT) form as follows:

$$
y=\mathbf{X} \beta+\frac{1}{\lambda} u
$$

where $y$ is the logged time until failure (i.e. duration), $X$ is a vector of covariates, and $u$ is the stochastic error, scaled by a shape parameter $\lambda$ that denotes the shape of the baseline hazard. Since $u$ is assumed to be i.i.d., given some distribution, it follows that such a model will lead to biased estimates when the observations are not sampled independently of one another. This is in contrast to our theoretical model where the fighting duration of rebel organization $y_{i}$ depends on the fighting durations of all other organizations $y_{j \neq i}$, and vice-versa.

As shown by Hays and Kachi (2015), if information about the interdependence structure is available, it is possible to overcome the independence assumption for event history models 
by introducing an endogenous spatial lag:

$$
y=\rho \mathbf{W} y+\mathbf{X} \beta+\frac{1}{\lambda} u,
$$

where $\mathbf{W}$ is an $n \times n$ connectivity matrix that specifies dependencies between pairs of rebel organizations. Assuming that the interdependence follows a monotonic functional form, $\rho$ provides an estimate of the interdependence between rebel organizations. Due to its analogy in the time-series analysis, this type of model is referred to as a spatial lag or spatially autoregressive model (SAR). Appendix A derives the maximum likelihood estimator based on the reduced form $y=(\mathbf{I}-\rho \mathbf{W})^{-1}\left(\mathbf{X} \beta+\frac{1}{\lambda} u\right)$. We emphasize that an endogenous spatial lag accommodated by this estimator 'solves' for simultaneity in rebel behavior and their ability to form expectations about future behavior. By contrast, if we simply introduced the spatial lagged term as a right hand side variable in standard (non-spatial) estimator, this would assume non-simultaneous behavior that is inconsistent with the notion of strategic interdependence, and only conditions on past behavior. Put differently, if actors behave strategically, the naïve, non-simultaneous estimator will yield biased inferences.

Non-aligned interdependent durations. The introduced spatial duration model is perfectly suitable in instances where all rebel organizations enter their respective conflicts at the same time, implying that all organizations were active from the beginning of the conflict. However, empirically this is not the case and it is common that rebel organizations join the fighting at later stages of a conflict and/or end their fighting efforts early. These dynamics make it necessary to adapt the above estimator (Hays and Kachi, 2015; Hays, 2009) to accommodate non-aligned duration through a specific setup of the connectivity matrix $\mathbf{W}{ }^{7}$

In addressing non-aligned interdependent fighting durations, we first rank-order all rebel organizations according to their date of entry. Therefore, $i=\{1, \ldots, N\}$ becomes a rank indicator, such that $i=1$ is the first mover, $i=2$ is the second mover, until the $n$th mover.

\footnotetext{
${ }^{7} \mathrm{~A}$ further obstacle originates from the fact that these models cannot easily deal with censored observations. Our proposed solution avoids dealing with censoring (or TVCs for that matter), and relies on non-censored observations only.
} 
Again, let $y_{i}$ denote the fighting duration of rebel organizations, whereas $z_{i}$ indicates the conflict entry time, that is the time since the start of the conflict until rebel organization $i$ enters. Figure 2 illustrates this notation for a hypothetical example of four rebel organizations.

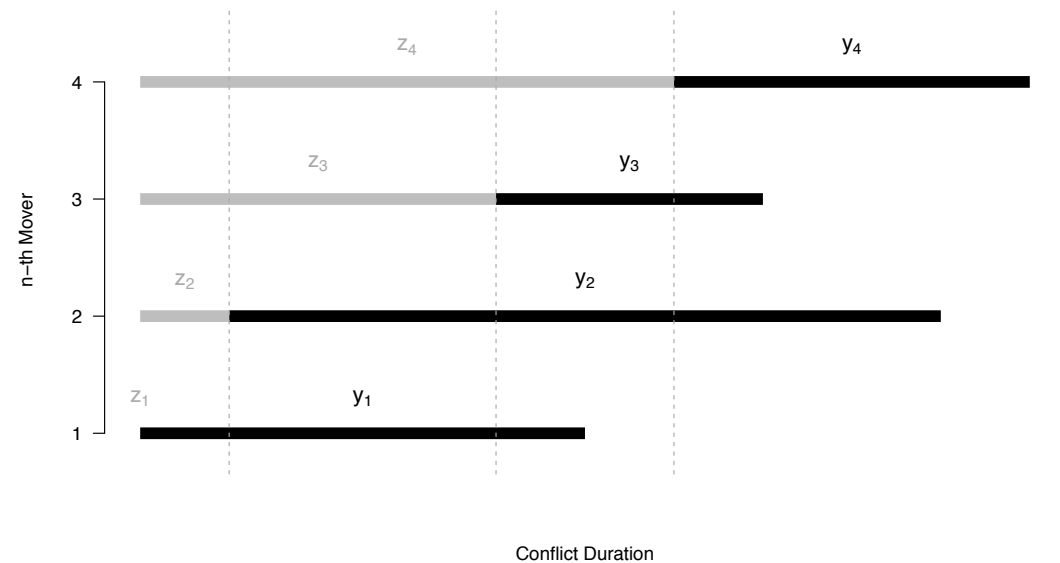

FiguRE 2. Non-Aligned fighting durations in a hypothetical conflict with four rebel organizations. The fighting durations of each individual rebel organization $y_{i}$ are represented as black bars, while the time until entering the conflict $z_{i}$ is illustrated by grey bars. Rebel organizations are rank-ordered by their date of entrance.

The main assumption in the theoretical model is that rebel organizations have expectations about the behavior of other active organizations. This implies that the first mover has expectations about the fighting durations of all subsequent rebel organizations entering the conflict:

$$
y_{1} \propto \sum_{j=2}^{n} y_{j}
$$

The second-mover, however, conditions her fighting duration on (1) how much longer she expects the first-mover organization to continue fighting, and (2) the expected fighting durations of subsequent movers. In other words, she considers the full durations of rebel organizations $i=3 \ldots N$, but only the part of the fighting duration of the first-mover that extends beyond her own entering time $z_{2}$. Formally this implies:

$$
y_{2} \propto y_{1}-z_{2}+\sum_{j=3}^{n} y_{j}
$$


Generalizing this pattern to the n-player setting, the general form of the rebel organizations' interdependencies can be now be written as follows:

$$
y_{i} \propto \sum_{j=1}^{i-1}\left(y_{j}-z_{i}\right)+\sum_{k=i+1}^{n} y_{k}
$$

Having specified the connectedness of individual fighting durations, we can construct an appropriate connectivity matrix $\mathbf{W}$ and derive our full model. Since our endogenous spatial lag not just involves fighting times but also conflict entry times, we follow a setup that resembles that of simultaneous equations. The resulting model can be thought of as a hybrid between a standard spatial and a simultaneous equation model. Note, however, that our estimator does not rely on instrumental variables, as we estimate only one equation. Rather, we show that the interdependence as given in Equation 12 can be constructed in matrix form through such a setup. The construction of the respective $\mathbf{W}$ matrix can be found in the Appendix.

\section{DATA}

Our empirical analysis is based on the Non-State Actors in Intra-State Conflicts Dataset (NSA version 3.4) (Cunningham, Gleditsch and Salehyan, 2009, 2013), which identifies rebel organizations that have been involved in armed conflicts with at least 25 casualties in a calender year. The NSA data set builds upon the Uppsala/PRIO Armed Conflict Data (Gleditsch et al., 2002) and generates a population of 477 government-rebel dyads from 1946 through 2011. Cunningham, Gleditsch and Salehyan (2009) focus on rebel organizations that were clearly active in fighting and have a distinct leadership structure. Based on their dyad indicators, we generate a start and end date for each conflict dyad. To accommodate our statistical estimator we drop all right-censored cases, leaving us with 327 unique governmentrebel dyads, with some appearing multiple times during a conflict. This creates 379 unique observations. The data set also provides conflict IDs, which we use to construct our connectivity matrix $\mathbf{W}$, i.e. assuming that rebel organizations that are simultaneously active in the same conflict potentially exhibit strategic interdependence. Our sample includes 153 
distinct conflicts, 72 of which are comprised of more than one rebel organization during their duration.

Outcome variable: Fighting time. In our empirical analysis we distinguish between the fighting time and the conflict entry time of rebel organizations. The dependent variable fighting time is the period in which a rebel organization actively takes part in the armed conflict. Given our operationalization of interdependent outcomes (see Equation 12), conflict entry time is also required and is defined as the time until a rebel organization joins the armed conflict. Thus, through the spatial lag, conflict entry time is also an outcome variable, but is treated as exogenous. This assumption allows us to enter waiting as an explanatory variable to account for the timing of conflict entry. ${ }^{8}$ Fighting and conflict entry times of rebel organizations are measured in calendar time, i.e. days. The conflict entry time for the first rebel group is always zero. ${ }^{9}$

Control variables. While the time until entry is one measure to evaluate the effect first or late movers have on fighting durations, we also control for the actual ordering of entry into the conflict. Hence, we generate a variable that simply orders rebel organizations by their respective entry time from one to the number of overall rebel organizations ever appearing in a conflict.

In our model specification, we also include a number of variables that scholars associate with the fighting durations of rebel organizations and that might be important confounders or drivers of strategic interdependence. Most importantly, the veto player theory proposed by Cunningham (2006) suggests that conflicts characterized by multiple actors tend to last

\footnotetext{
${ }^{8}$ Ideally we would endogenize both waiting and fighting times through simultaneous equations (see Hays and Kachi (2015)). However, to do so we require suitable instruments for identification, i.e. at least one variable that is associated with either outcome, but not the other. Unfortunately, we are not able to plausibly identify such a variable. This implies that our results, in this regard, are vulnerably to potential endogeneity concerns.

${ }^{9}$ To accommodate the log specification (which does not allow for values of zero) we added one day to each conflict entry time. Choosing even smaller values did not alter the results.
} 
longer. While we believe that measuring the number of actors in a conflict merely measures constellations rather than strategic interactions, we include the number of active rebel organizations for each rebel organization at their respective time of entrance.

Following Cunningham, Gleditsch and Salehyan (2009), we control for a number of rebel strength measures. We include a dummy of whether the rebel organizations are able to control territory, which is generally associated with shorter conflicts (Cunningham, Gleditsch and Salehyan, 2009). Additionally, we indicate whether a rebel organization has a legal political wing (Cunningham, Gleditsch and Salehyan, 2009). We interpret a legal political wing as a proxy for public support and political power of the rebel organization.

Fighting dynamics are likely to be dependent on state characteristics such as military power, political institutions, and geographic characteristics. In order to address these relatively constant state characteristics we include country dummy variables in all our models. This also has the advantage that we do not need to impute missing information on state strength (e.g. GDP per capita) or military strength (e.g. troop numbers).

We also include indicators of whether rebel organizations are splinter groups or are part of an over-arching alliance, accounting for particular dynamics that might be associated with fragmentation and coalition behavior (Bakke, Cunningham and Seymour, 2012; Akcinaroglu, 2012; Christia, 2012). We code splinter and alliance characteristics based on the UCDP actor data (Petterson and Themnér, 2012) coding and using UCDP dyadic data to link this information (Harbom, Melander and Wallensteen, 2008). Finally, we account for the fact that previous conflict outcomes are argued to impact on future conflict behavior (Walter, 2004; Chiba, Metternich and Ward, 2015) and that the incompatibility of conflict, especially secessionist conflicts, affect conflict duration. Summary statistics for all variables can be found in the Appendix, Table B2.

\section{RESUlTS AND INTERPRETATION}

In this section we report our empirical results. These generally support our theoretical argument about positive interdependence (competition) among rebel organizations' fighting 
times. However, in secessionist conflicts, where the conflict incompatibility has public good characteristics, such complementarities in rebel fighting durations are partially offset through a substitution logic, i.e. free-riding.

We compare estimates and fit from a conventional (non-strategic) model to those of our spatial (strategic) estimator. Based on AIC comparisons, we find that the Weibull distribution provides a best fit to the data (alternative distributional assumptions are presented in the appendix; substantive results remain unchanged); hence we report results for Weibull models. All models are estimated in the Accelerated Failure Time (AFT) form. Thus, positive coefficients imply that higher values of an independent variable increase the fighting duration of a rebel-government dyad, while negative estimates indicate that higher values of a variable are related to shorter fighting durations. The significance of each estimate is assessed by two-tailed tests.

Main results. We provide our main findings in Table 2. Our discussion focuses on the findings regarding interdependence and strategic interaction between rebel organizations. (We briefly comment on the results from the covariates below.)

We first estimate a (standard) non-strategic Weibull model which does not account for the interdependence between the rebel organizations, but includes the commonly used 'veto' variable measuring the number of other rebel organizations active at the beginning of a government-rebel episode. In line with previous findings (Cunningham, 2006), we find that higher numbers of active rebel organizations increase the fighting duration of rebel organizations. We then estimate the same model with our spatial Weibull duration estimator and initially exclude the 'veto' variable. This model explicitly addresses strategic (spatial) interdependence through the spatial parameter $\rho$ - which is positive and fairly precise, indicating a positive interdependence between rebel organizations' fighting duration. This provides initial support for our theoretical argument that fighting durations are strategic complements. In other words, increased fighting durations of one rebel organization leads to longer fighting spells of others. Moreovoer, given an identical number of estimated parameters, the lower $\mathrm{AIC}$ and BIC values in the spatial compared to the standard model suggest an improved fit. 
TABLE 2. Estimates for the main fighting duration models in accelerated failure time format. Standard errors are provided in parenthesis. Outcome variable is the fighting duration of rebel organizations measured in days.

\begin{tabular}{|c|c|c|c|c|c|}
\hline & Veto Model & Spatial Model & Spatial Veto Model & Secession Model & Non-Secession Model \\
\hline \multirow[t]{2}{*}{ Intercept } & $6.06^{* * *}$ & $6.05^{* * *}$ & $6.05^{* * *}$ & $6.19^{* * *}$ & $6.31^{* * *}$ \\
\hline & $(0.34)$ & $(0.35)$ & $(0.33)$ & $(1.77)$ & $(0.37)$ \\
\hline \multirow[t]{2}{*}{ Time until Entry ${ }_{l o g}$} & -0.02 & -0.03 & -0.03 & -0.05 & 0.01 \\
\hline & $(0.03)$ & $(0.03)$ & $(0.03)$ & $(0.05)$ & $(0.03)$ \\
\hline \multirow[t]{2}{*}{ Splinter } & 0.03 & -0.02 & -0.02 & 0.19 & -0.12 \\
\hline & $(0.25)$ & $(0.25)$ & $(0.26)$ & $(0.47)$ & $(0.33)$ \\
\hline \multirow{2}{*}{ Alliance } & -0.37 & $-0.52^{*}$ & $-0.52^{*}$ & -0.14 & -0.51 \\
\hline & $(0.30)$ & $(0.30)$ & $(0.30)$ & $(0.65)$ & $(0.35)$ \\
\hline \multirow[t]{2}{*}{ Previous.Victory } & $0.83^{* * *}$ & $0.77^{* * *}$ & $0.77^{* * *}$ & 0.41 & $0.92^{* * *}$ \\
\hline & $(0.21)$ & $(0.20)$ & $(0.20)$ & $(0.76)$ & $(0.27)$ \\
\hline \multirow[t]{2}{*}{ Previous.Agreement } & 0.04 & 0.07 & 0.06 & 0.64 & 0.13 \\
\hline & $(0.16)$ & $(0.15)$ & $(0.16)$ & $(0.53)$ & $(0.19)$ \\
\hline \multirow[t]{2}{*}{ Legal.Political.Wing } & $-0.58^{* * *}$ & $-0.55^{* *}$ & $-0.54^{* *}$ & $-0.67^{*}$ & -0.37 \\
\hline & $(0.22)$ & $(0.22)$ & $(0.22)$ & $(0.40)$ & $(0.28)$ \\
\hline \multirow[t]{2}{*}{ Rebel.Strength } & 0.18 & 0.18 & 0.18 & 0.51 & 0.06 \\
\hline & $(0.15)$ & $(0.15)$ & $(0.14)$ & $(0.46)$ & $(0.17)$ \\
\hline \multirow[t]{2}{*}{ Veto } & 0.17 & & -0.03 & 0.11 & 0.11 \\
\hline & $(0.14)$ & & $(0.15)$ & $(0.32)$ & $(0.19)$ \\
\hline \multirow[t]{2}{*}{ Order } & $-0.14^{* *}$ & $-0.14^{* *}$ & $-0.13^{* *}$ & -0.07 & $-0.20^{* *}$ \\
\hline & $(0.06)$ & $(0.05)$ & $(0.06)$ & $(0.08)$ & $(0.08)$ \\
\hline \multirow[t]{2}{*}{ Secession } & $0.53^{* *}$ & $0.55^{* *}$ & $0.54^{* *}$ & & \\
\hline & $(0.24)$ & $(0.23)$ & $(0.23)$ & & \\
\hline Country Dummies & yes & yes & yes & yes & yes \\
\hline \multirow[t]{2}{*}{ Scale $_{l o g}$} & $0.30^{* * *}$ & $0.29^{* * *}$ & $0.29^{* * *}$ & 0.10 & $0.29^{* * *}$ \\
\hline & $(0.04)$ & $(0.04)$ & $(0.04)$ & $(0.08)$ & $(0.05)$ \\
\hline \multirow[t]{2}{*}{$\rho$} & & $0.10^{* * *}$ & $0.10^{* * *}$ & 0.02 & $0.08^{* *}$ \\
\hline & & $(0.03)$ & $(0.03)$ & $(0.05)$ & $(0.04)$ \\
\hline Log-Likelihood & -725.10 & -720.00 & -719.98 & -180.29 & -521.00 \\
\hline $\mathrm{N}$ & 379 & 379 & 379 & 107 & 272 \\
\hline $\mathrm{AIC}$ & 1594.21 & 1584.01 & 1585.96 & 428.58 & 1175.99 \\
\hline $\mathrm{BIC}$ & 1877.71 & 1867.51 & 1873.40 & 519.46 & 1417.58 \\
\hline
\end{tabular}

The third model is again a spatial Weibull model, but also includes the 'veto' variable. The estimates suggest that interdependency between rebel organizations is better captured through the spatial framework, as compared to simply accounting for the constellation in the conflict. In fact, controlling for the number of veto players in a spatial Weibull model leaves us with almost the same estimate for $\rho$, but with a small but negative (and imprecise) estimate for the number of active rebel organizations. Accounting for the strategic interdependence even reverses the sign for the effect of the total number of rebel organizations (i.e. veto players). However, this does not necessarily refute the theoretical foundation of the veto player perspective (Cunningham, 2006). The veto player theory is inherently strategic and it is therefore likely that our endogenous spatial lag (also) captures these effects. In addition, any non-linearity in the effect of the number of veto players on conflict duration could 
be partially captured by duration dependence between rebel organizations. Overall, the results supports our argument that it is indeed strategic interaction between actors rather than simply configurations that drive conflict duration in multi-actor civil wars. This result should encourage future research on multi-party conflicts to account not only for the number of actors but the endogenous nature of strategic interaction.

To further corroberate the strategic logic, we explicitly compare conflicts with incompatibilities that (also) incentivize substitution effects which we expect to (partially) offset strategic competition. Thus, we estimate two additional models for which we split the sample between separatist and non-separatist conflicts. We find that strategic interdependence $(\rho)$ remains positive and significant in non-secessionist conflicts, while the coefficient is nearly zero in secessionist conflicts, suggesting that incentives to free-ride at least in part offset incentives for competition. ${ }^{10}$

We also comment on the control variables. Rebel organizations with a political wing affiliated to them experience shorter dyad durations. Organizations within secessionist conflicts tend to fight longer. While the actual timing of entry does not seem to impact fighting durations, we do find evidence that the ordering does matter. We find that early movers seem to fight longer than late movers. Previous victories of a government increase fighting durations, which might point to a particular type of rebel organization that fights previously successful governments. Alliances also seem to fight shorter durations, which might be related to the strength of alliances or simply the fact that they form later on in conflict. Splinter groups do not exhibit such a clear empirical pattern, which could be contributed to the coding of UCDP alliances and splintering, which requires a fairly formal statement of joining or separation. Hence, many dynamics that are implied in the existing literature on rebel alliances and fragmentation (e.g., Bakke, Cunningham and Seymour, 2012) are probably not fully captured by this measure.

\footnotetext{
${ }^{10}$ Testing for the difference between coefficients according to Clogg, Petkova and Haritou (1995), we also find no difference between the two estimated $\rho \mathrm{s}$
} 
In sum, we find consistent support for our hypothesis of positive duration interdependence between rebel organizations. This suggests that multi-actor constellations matter because of strategic dynamics that arise between rebel organizations, not because such constellations are more difficult to resolve per se. In other words, our results bolster the strategic perspective through a more direct test of the full extent of strategic dynamics that is implied in, e.g., Cunningham (2006), Akcinaroglu (2012), or Cunningham (2013), but not adequately tested through measures of mere constellations.

Model fit evaluation. We further investigate our findings by comparing the naïve (nonstrategic) Weibull model (Model 1) with the spatial (strategic) Weibull model (Model 3) in regard to their ability to predict fighting durations. At first glance the distributions of predicted durations of the naïve (orange) and spatial (purple) do not seem to differ much (see Figure 3 panel (a)) and slightly over-predict observed durations (black line) on average. However, looking at the relative advantage of the respective models in predicting durations (see Figure 3 panel (b)), we can uncover an interesting pattern. The non-strategic Weibull model (Model 1) outperforms the strategic Weibull model (Model 3) when predicting shorter fighting durations, while the strategic Weibull model (Model 3) is closer to the observed values when rebel organizations fight for a longer period of time.

On average, the strategic Weibull model (Model 3) outperforms the non-strategic Weibull model (Model 3) when calculating the root mean squared error for the naïve (RSME $=$ 1796.92) and the spatial $(\mathrm{RSME}=1714.01)$ model. In addition, when scoring which model is closer to the observed duration (Figure 3c), the spatial model has a clear advantage compared to the naïve model. We also analyze the absolute difference of the observed and estimated durations, which can be found in the Appendix. In conclusion, there seems to be a pattern that the spatial model especially outperforms the naïve model, when rebel organizations fight for more than 10 years (about 10 percent or rebel organization spells) (Figure 3b). This provides further evidence that the spatial model accounts for duration dynamics that are not captured by the non-strategic estimation approach. 


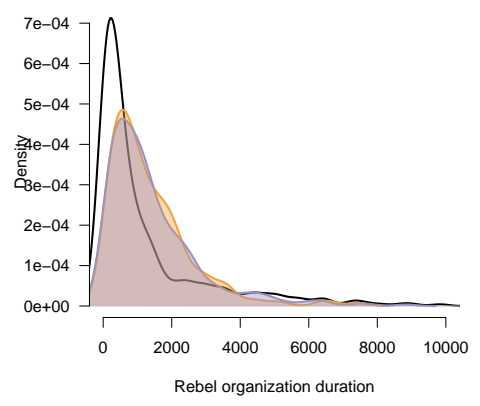

(a) Predicted densities

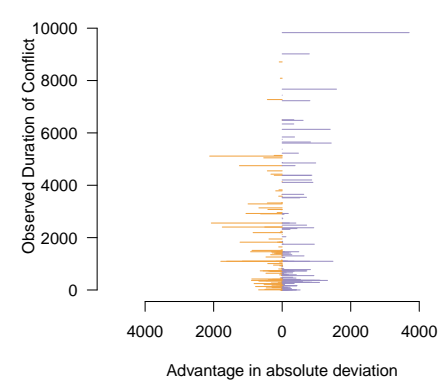

(b) Relative advantage

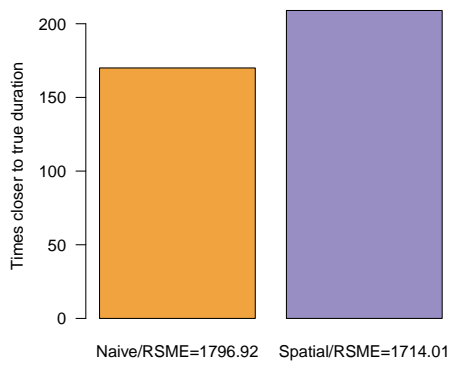

(c) Case-wise comparison

Figure 3. Model fit and model fit assessment comparing Models 1 and 3 (K-dyads vs. spatial (strategic) Weibull). In all panels orange refers to Model 1, while purple pertains to Model 3.

Secessionist vs. non-secessionist conflicts. To provide further support for the argument that the endogenous spatial effect $\rho$ is evidence for fighting durations as strategic complements, we analyze differences between secessionist and non-secessionist conflicts. We argued in the theoretical section that conflicts with incompatibilities that feature more public good characteristics (such as secessionist conflicts) should be increasingly driven by substitution effects. Using the secessionist conflict type coding from the Non-State Actor dataset (Cunningham, Gleditsch and Salehyan, 2009), we split the sample into rebel organizations involved in secessionist and non-secessionist conflicts.

Comparing model fit of the secessionist and non-secessionist conflicts, despite a smaller and less precise $\rho$ in the secessionist model (Model 4 in Table 2) than in the non-secessionist model (Model 5 in Table 2), model fit is better in the spatial strategic model compared to the naïve non-strategic model (estimates for the non-strategic versions of the secessionist and non-secessionist model can be found in the Appendix Table B3). The RMSE improves in both the secessionist and non-secessionist conflict sample when estimating the spatial strategic model (see panels $\mathrm{c}$ and $\mathrm{f}$ in Figure 4). In the non-secessionist sample the spatial model provides a prediction closer to the observed fighting duration in 142 out of 272 episodes $(0.52 \%)$ and in the secessionist sample outperforms the naïve non-strategic model in 65 out of 107 episodes (0.61\%). The model predictions differ in regard to the length of rebel 


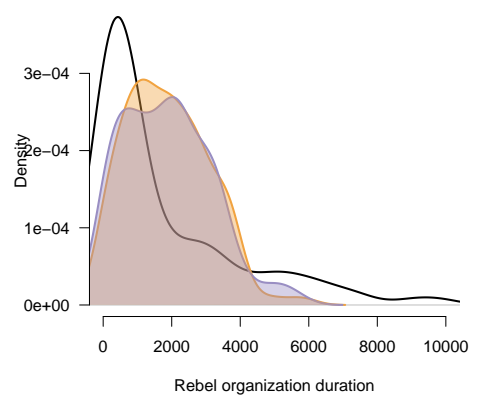

(a) Predicted densities for separatist conflict sample.

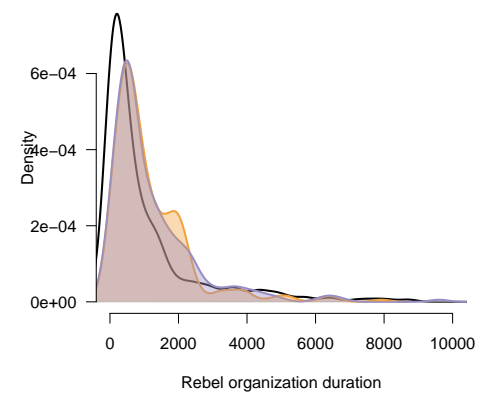

(d) Predicted densities for nonseparatist conflict sample.

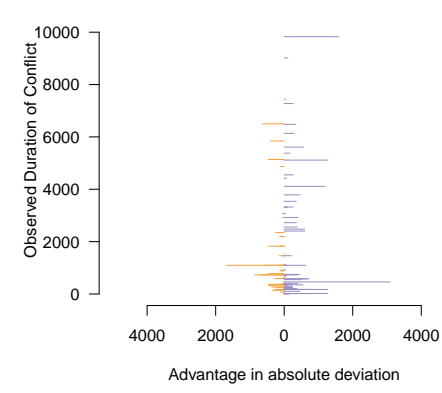

(b) Relative advantage for separatist conflict sample.

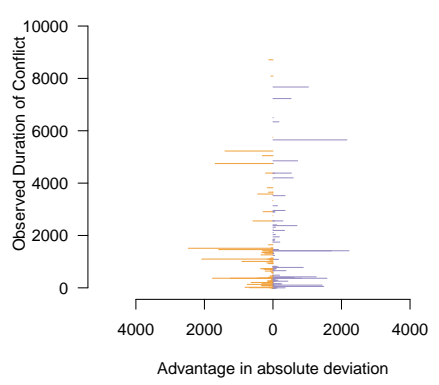

(e) Relative advantage for nonseparatist conflict sample.

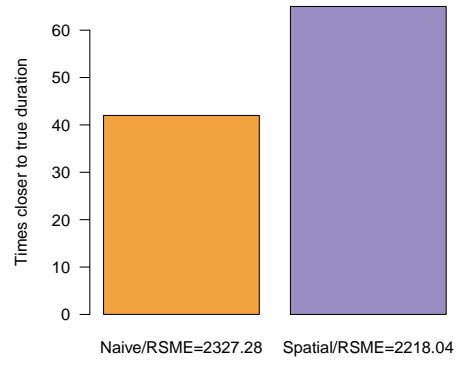

(c) Case-wise comparison for separatist conflict sample.

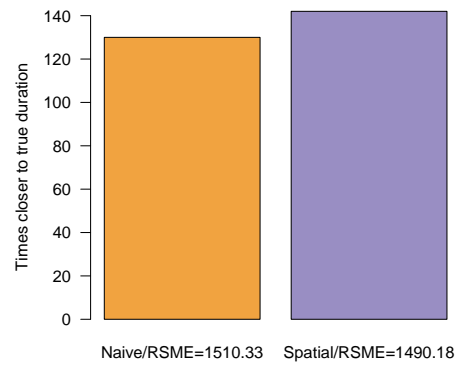

(f) Case-wise comparison for non-separatist conflict sample.

Figure 4. Model fit assessment. Top panels compare the separatist spatial duration model (Model 4) with its non-strategic version. Bottom panels compare the non-separatist duration model (Model 5) with its non-strategic version. In all panels orange refers to the spatial strategic Weibull models while orange pertain to the naïve non-strategic Weibull models.

organization fighting spells. The non-secessionist models display similar properties as the pooled model, in the sense that long durations are better predicted by the spatial strategic model, while short rebel organization episodes are slightly better predicted by the naïve nonstrategic model (see Figure 4b). This pattern cannot be observed in the secessionist sample (see Figure 4e).

The long run effect of interdependence. To better assess the extent to which the interdependence between rebel organizations actually impacts on fighting durations, we simulate 
the long run effects of the spatial dependence. Without these comparative statics it is difficult to gauge the extent to which the estimated $\rho$ coefficient impacts the overall fighting dynamics. To simulate long run effect of $\rho$ we take the estimated coefficients from Model 3 (Table 2) and fix all explanatory variables at their median values. We then consider a hypothetical conflict with four strategic rebel organizations that start fighting in the same time period. We implement the data generating process of the spatial Weibull (see Appendix) and draw from this process 10,000 times to assess differences in the median duration under three scenarios $(\rho=\{-0.1,0,0.1\})$. The first scenario, $\rho=-0.1$, implies substitution effects between the rebel organizations, while the complemetarity scenario, $\rho=0.1$, pertains to the largest coefficient that we have estimated in the presented models. The results are displayed in Figure 5 clearly showing that an increase in $\rho$ increases the median fighting time of individual rebel organizations. In this simulation the median duration increases by about 1 year when comparing $\rho=0$ to the empirically estimated $\rho=0.1$. This highlights that the magnitude of the effect of strategic interdependence is fairly substantial and provides further evidence that studies interested in the behavior of rebel organizations need to take into account their interdependency.

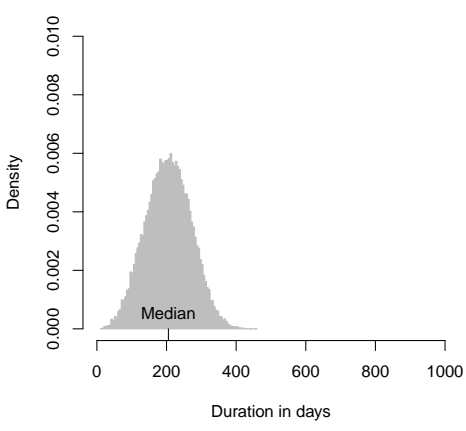

(a) $\rho=-0.1$, Median $=205$

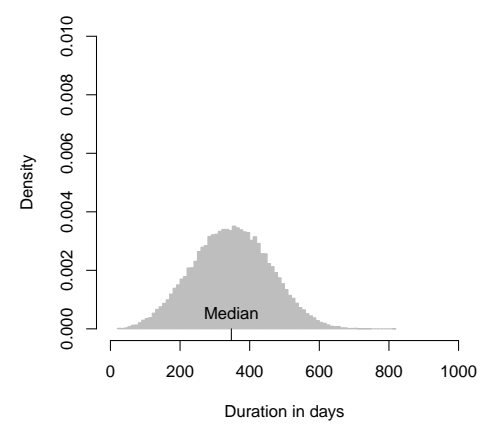

(b) $\rho=0$, Median $=347$

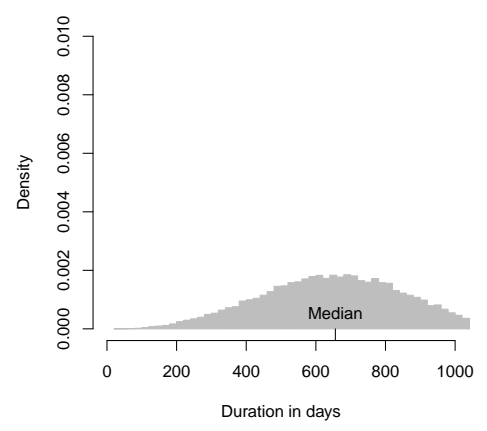

(c) $\rho=0.1$, Median $=656$

Figure 5. Simulated fighting durations based on model estimates in a hypothetical conflict with four interdependent rebel organizations holding all explanatory variables at their median value. 
Robustness. We employ two alternative parameterizations using the lognormal and loglogistic distribution to minimize the risk of any artifacts due to our parametric assumptions (see Table B4). Since both distributions are two parameter distributions, we can compare model fit directly by comparing log-likelihood values. In this comparison, the spatial Weibull (Model 3 in Table 2) demonstrates the best fit to our data. Generally, we find that the Weibull parameterization provides a much better goodness of fit to the data than the loglogistic and log-normal, which is suggested by the consistently lower log-likelihood values. Thus, we tend to place higher confidence in the Weibull results. However, it can be noted that our main result of a positive and precise $\rho$ estimate applies across all models. The independence effect seems to be slightly stronger in the lognormal model than in the loglogistic model.

Another concern might be that conflict outcomes might influence the fighting dynamics. Since dyads within one conflict can have different outcomes, we are not able to analyze separate samples because we would lose the interdependency structure. However, we can include outcomes as a control variable. While this is not ideal, we demonstrate that the complementarity dynamics are not affected by controlling for outcomes on the rebel organization level (see Appendix Table B5).

We also provide initial insights into whether stronger or weaker rebels react more to the spatial effects. In doing this we estimate two separate models (see Appendix Table B6). The first model manipulates the $W$ matrix such that only strong rebel organizations (coded as similarly strong or stronger than the government by the NSA data) receive the externalities from other rebels' fighting durations. In the second model, we do the opposite, by only allowing weaker rebel organizations (coded as weaker than the government by NSA) to be affected by other rebel organizations' fighting durations. We find that weaker rebel organizations (328 out of 379) react more strongly to the fighting durations of other rebels than stronger organizations (51 out of 379 ).

Finally, we also ensure that the endogenous spatial effect is not simply picking up on the fact that some rebel organizations are within multi-party conflicts while others are not. We 
therefore re-estimate Models 1-3 with a sample that only contains rebel organizations nested in multi-party conflicts. The estimated $\rho$ coefficients are almost identical and robust to the exclusion of single rebel organizations fighting the government (see Appendix Table B7). ${ }^{11}$

\section{Discussion AND Conclusion}

When should a rebel organizations lay down their weapons? We argue that rebel organizations have incentives to remain mobilized until the end of a conflict because it allows them to shape the post-conflict aftermath by maintaining their (i) power to negotiate, (ii) power to spoil, (iii) power to enforce, and (iv) power to protect. We argue that these incentives lead to strategic complementarities that outweigh potential substitution effects.

Strategic interdependence between rebel organization is widely acknowledged in the theoretical literature (Cunningham, 2006; Cunningham, Gleditsch and Salehyan, 2009; Fearon, 2004; Akcinaroglu, 2012; Fjelde and Nilsson, 2012; Cunningham, Bakke and Seymour, 2012; Cunningham, 2013; Nygård and Weintraub, 2015; Wood and Kathman, 2015). We here provide an empirical framework to test the implications of strategic theories in context of fighting durations in multi-actor civil wars. Broadly speaking, we articulated a need to narrow the gap between theoretical accounts of rebel organizations' behavior and its empirical testing. The literature on civil war duration has made enormous progress in the past twenty years. From country and conflict based studies, we gained insights on the role of government strength (Mason and Fett, 1996; Balch-Lindsay and Enterline, 2000; DeRouen Jr. and Sobek, 2004), geographic factors (Buhaug, Gates and Lujala, 2009), and economic development (Collier, Hoeffler and Soderbom, 2004). Attempting to account for 2-actor theories (e.g., Fearon, 2004) new data projects have collected dyadic data (Harbom, Melander and Wallensteen, 2008; Cunningham, Gleditsch and Salehyan, 2009) that provide the foundation for novel insights into how rebel characteristics and their relationship to the government impact on conflict duration. However, without accounting for the strategic interdependence

\footnotetext{
${ }^{11}$ This project benefited greatly from the open source R community. Estimation relies on 'maxLik' package developed by Henningsen and Toomet (2011). Presentation of results is supported by 'texreg' (Leifeld, 2013).
} 
between rebel organizations and dyads in empirical applications, important dynamics that are implied by multi-actor theories (Bakke, Cunningham and Seymour, 2012; Cunningham, 2011; Akcinaroglu, 2012; Christia, 2012; Findley and Rudloff, 2012; Fjelde and Nilsson, 2012; Nygård and Weintraub, 2015; Wood and Kathman, 2015) cannot be adequately modeled and tested. We especially highlighted that merely measuring conflict constellations (e.g. the number of rebel organizations) does not capture the underlying data-generating mechanisms that are assumed by strategic theories.

Our theoretical argument that strategic complementarities among rebel organizations impact on fighting duration finds strong support in our empirical study. Accounting for interdependencies by implementing a spatial-duration estimation approach allows us to uncover these complementarities in fighting durations. From a theoretical perspective these findings can be interpreted as support for the argument that in multi-party conflicts, rebel organizations not only compete with the government, but also with all other rebel organizations that challenge the state to maintain their (i) power to negotiate, (ii) power to spoil, (iii) power to enforce, and (iv) power to protect. Clearly, there are limitations in the extent to which we can make claims of whether the proposed dynamics are the only logic driving fighting duration. As Cunningham, Bakke and Seymour (2012) highlight, it is very likely that "dual contests" are taking place simultaneously, which provide incentives for both cooperation and competition among rebel organizations. However, in aggregate our empirical findings suggest that complementarities behavior outweighs substitution dynamics in the context of civil conflicts.

We emphasize that our study is not able to uncover the full heterogeneity of complementarity and substitution effects within conflicts. Indeed, we have merely estimated average effects across all dyads in our sample through the global parameter $\rho$ (although we distinguish by conflict type). We recommend that future work addresses-theoretically and empirically-variation that might exist between dyads. The trade-off between substitution and complementary might differ systematically depending on specific rebel characteristics. For example, we would expect that relatively weaker rebel organizations are generally more 
affected by spatial stimuli. In addition, further differences may also exist between conflicts, as our preliminary analysis of secessionist vs. non-secessionist conflicts demonstrates. Indeed, we would expect that more specific theory (under specific circumstances) would lead to stronger estimates of interdependence, as compared to the 'crude' estimates presented in this study.

Finally, our study demonstrates that rebel organization interdependence is not merely nuisance, but plays an important role in explaining rebel organizations' fighting durations. We contribute to the literature by theoretically stressing the strategic interactions between rebel organizations and proposing an empirical approach, which explicitly models the interdependence of fighting durations. More generally, this paper not only pertains to the study of civil war, but can be applied in other political science contexts that entail interdependencies of non-aligned durations. These might include US primaries (Abramson et al., 1992) where several candidates try to outlast each other, regional democratization (Svolik, 2008) where democratic consolidation is dependent on regional consolidation, and of course behavior between alliance members (Morrow, 1991) in the context of international relations. Our study enables future research that explores duration dependence in these common strategic settings.

\section{REFERENCES}

Abramson, Paul R, John H Aldrich, Phil Paolino and David W Rohde. 1992. "?Sophisticated? Voting in the 1988 Presidential Primaries." American Political Science Review $86(01): 55-69$.

Akcinaroglu, Seden. 2012. "Rebel Interdependencies and Civil War Outcomes." Journal of Conflict Resolution 56(5):879-903.

Bakke, Kristin M., Kathleen Gallagher Cunningham and Lee J. M. Seymour. 2012. "A Plague of Initials: Fragmentation, Cohesion, and Infighting in Civil Wars." Perspectives on Politics 10(02):265-283. 
Balch-Lindsay, Dylan and Andrew J. Enterline. 2000. "Killing time: The world politics of civil war duration, 1820-1992." International Studies Quarterly 44(4):615-642.

Bapat, Navin A. and Kanisha D. Bond. 2012. "Alliances between Militant Groups." British Journal of Political Science 42(04):793-824.

Beck, Nathaniel, Kristian Skrede Gleditsch and Kyle Beardsley. 2006. "Space is more than geography: Using spatial econometrics in the study of political economy." International Studies Quarterly 50(1):27-44.

Bloom, Mia. 2005. Dying to kill: The allure of suicide terror. Columbia University Press.

Bramoullé, Yann and Rachel Kranton. 2007. "Public goods in networks." Journal of Economic Theory 135:478-494.

Bramoullé, Yann, Rachel Kranton and Martin D'Amours. 2014. "Strategic Interaction and Networks." American Economic Review 104(3):898-930.

Buhaug, Halvard and Kristian Skrede Gleditsch. 2008. "Contagion or confusion? Why conflicts cluster in space." International Studies Quarterly 52(2):215-233.

Buhaug, Halvard, Scott Gates and Päivi Lujala. 2009. "Geography, rebel capability, and the duration of civil conflict." Journal of Conflict Resolution 53(4):544-569.

Chiba, Daina, Nils W. Metternich and Michael D. Ward. 2015. "Every Story Has a Beginning, Middle, and an End (But Not Always in That Order): Predicting Duration Dynamics in a Unified Framework." Political Science Research and Methods FirstView.

Cho, Wendy K. Tam. 2003. "Contagion Effects and Ethnic Contribution Networks." American Journal of Political Science 47(2):368-387.

Christia, Fotini. 2012. Alliance Formation in Civil War. Cambridge: Cambridge University Press.

Clayton, Govinda. 2013. "Relative rebel strength and the onset and outcome of civil war mediation." Journal of Peace Research 50(5):609-622.

Clogg, Clifford C, Eva Petkova and Adamantios Haritou. 1995. "Statistical methods for comparing regression coefficients between models." American Journal of Sociology 100(5):1261-1293. 
Collier, Paul. 2000. Doing well out war: an economic perspective. In Greed $\&$ grievance: Economic agendas in civil wars, ed. Mats R Berdal and David Malone. Boulder: Lynne Rienner pp. 91-112.

Collier, Paul, Anke Hoeffler and Mans Soderbom. 2004. "On the duration of civil war." Journal of Peace Research 41(3):253-273.

Conrad, Justin and Kevin Greene. 2015. "Competition, differentiation, and the severity of terrorist attacks." The Journal of Politics 77(2):546-561.

Conrad, Justin M, Kevin T Greene, James Igoe Walsh and Beth Elise Whitaker. 2019. "Rebel Natural Resource Exploitation and Conflict Duration." Journal of Conflict Resolution $63(3): 591-616$.

Cunningham, David E. 2006. "Veto players and civil war duration." American Journal of Political Science 50(4):875-892.

Cunningham, David E., Kristian Skrede Gleditsch and Idean Salehyan. 2013. "Non-state actors in civil wars: A new dataset." Conflict Management and Peace Science 30(5):516531.

Cunningham, David, Kristian Skrede Gleditsch and Idean Salehyan. 2009. "It takes two: A dyadic analysis of civil war duration and outcome." Journal of Conflict Resolution $53(4): 570-597$.

Cunningham, Kathleen Gallagher. 2011. "Divide and Conquer or Divide and Concede: How Do States Respond to Internally Divided Separatists?" American Political Science Review 105(02):275-297.

Cunningham, Kathleen Gallagher. 2013. "Actor Fragmentation and Civil War Bargaining: How Internal Divisions Generate Civil Conflict." American Journal of Political Science $57(3): 659-672$.

Cunningham, Kathleen Gallagher and Katherine Sawyer. 2017. "Is Self-determination Contagious? A Spatial Analysis of the Spread of Self-Determination Claims." International Organization 71(3):585-604. 
Cunningham, Kathleen Gallagher, Kristin M. Bakke and Lee J. M. Seymour. 2012. "Shirts Today, Skins Tomorrow." Journal of Conflict Resolution 56(1):67-93.

Darmofal, David. 2009. "Bayesian spatial survival models for political event processes." American Journal of Political Science 53(1):241-257.

DeRouen Jr., Karl and David Sobek. 2004. "The dynamics of civil war: Duration and outcome." Journal of Peace Research 41(3):303-320.

Driscoll, Jesse. 2012. "Commitment Problems or Bidding Wars? Rebel Fragmentation as Peace Building." Journal of Conflict Resolution 56(1):118-149.

Fearon, James D. 2004. "Why some civil wars last so much longer than others?" Journal of Peace Research 41(3):275-301.

Findley, Michael G and Joseph K Young. 2015. "Terrorism, spoiling, and the resolution of civil wars." The Journal of Politics 77(4):1115-1128.

Findley, Michael and Peter Rudloff. 2012. "Combatant Fragmentation and the Dynamics of Civil Wars." British Journal of Political Science 42(04):879-901.

Fjelde, Hanne and Desirée Nilsson. 2012. "Rebels against Rebels: Explaining Violence between Rebel Groups." Journal of Conflict Resolution 56(4):604-628.

Fjelde, Hanne and Desiree Nilsson. 2018. "The rise of rebel contenders: Barriers to entry and fragmentation in civil wars." Journal of Peace Research 55(5):551-565.

Franzese, Robert J., Jr and Jude C. Hays. 2007. "Spatial Econometric Models of CrossSectional Interdependence in Political Science Panel and Time-Series-Cross-Section Data." Political Analysis 15(2):140-164.

Franzese, Robert J. and Jude C. Hays. 2008. "Interdependence in Comparative Politics: Substance, Theory, Empirics, Substance." Comparative Political Studies 41(4/5):742-780.

Gade, Emily Kalah, Mohammed M Hafez and Michael Gabbay. 2019. "Fratricide in rebel movements: A network analysis of Syrian militant infighting." Journal of Peace Research Forthcoming(OnlineFirst):1-15.

Galeotti, Andrea, Sanjeev Goyal, Matthew O. Jackson, Fernando Vega-Renondo and Leeat Yariv. 2010. "Network games." Review of Economic Studies 77:218-244. 
Gallop, Max. 2017. "More dangerous than dyads: how a third party enables rationalist explanations for war." Journal of Theoretical Politics 29(3):353-381.

Gates, Scott. 2002. "Recruitment and Allegiance: The Microfoundations of Rebellion." Journal of Conflict Resolution 46(1):111-130.

Gleditsch, Kristian Skrede. 2007. "Transnational dimensions of civil war." Journal of Peace Research 44(3):293-309.

Gleditsch, Kristian Skrede and Michael D. Ward. 2006. "Diffusion and the international context of democratization." International Organization 60(04):911-933.

Gleditsch, Nils Petter, Peter Wallensteen, Mikael Eriksson, Margareta Sollenberg and Havard Strand. 2002. "Armed conflict 1946-2001: A new dataset." Journal of Peace Research $39(5): 615-637$.

Harbom, Lotta, Erik Melander and Peter Wallensteen. 2008. "Dyadic Dimensions of Armed Conflict, 1946-2007." Journal of Peace Research 45(5):697-710.

Hays, Jude C. 2009. Bucking the system: Using simulation methods to estimate and analyze systems of equations with qualitative and limited dependent variables. St. Louis Area methods Meeting (SLAMM), April 24, 2009: .

Hays, Jude C. and Aya Kachi. 2015. Interdependent duration models in political science. In Quantitative Research in Political Science, ed. Robert J. Franzese. Vol. 5 London: Sage. Hays, Jude C., Emily U. Schilling and Frederick J. Boehmke. 2015. "Accounting for Right Censoring in Interdependent Duration Analysis." Political Analysis 23(3):400-414.

Henningsen, Arne and Ott Toomet. 2011. "maxLik: A package for maximum likelihood estimation in R." Computational Statistics 26:443-458.

König, Michael D, Dominic Rohner, Mathias Thoenig and Fabrizio Zilibotti. 2017. "Networks in conflict: Theory and evidence from the great war of africa." Econometrica 85(4):10931132.

Leifeld, Philip. 2013. "texreg: Conversion of Statistical Model Output in R to LATEX and HTML Tables." Journal of Statistical Software 55(8):1-24. 
Lichbach, Mark Irving. 1995. The Rebel's Dilemma. Ann Arbor: University of Michigan Press.

Mason, T. David and Patrick J. Fett. 1996. "How Civil Wars End: A Rational Choice Approach." Journal of Conflict Resolution 40(4):546-568.

Metternich, Nils W., Cassy Dorff, Max Gallop, Simon Weschle and Michael D. Ward. 2013. "Antigovernment Networks in Civil Conflicts: How Network Structures Affect Conflictual Behavior." American Journal of Political Science 57(4):892-911.

Morrow, James D. 1991. "Alliances and asymmetry: An alternative to the capability aggregation model of alliances." American Journal of Political Science pp. 904-933.

Murdoch, James D. and Todd Sandler. 2004. "Civil wars and economic growth: Spatial dispersion." American Journal of Political Science 48(1):138-151.

Nemeth, Stephen. 2014. "The Effect of Competition on Terrorist Group Operations." Journal of Conflict Resolution 58(2):336-362.

Nygård, Håvard Mokleiv and Michael Weintraub. 2015. "Bargaining Between Rebel Groups and the Outside Option of Violence." Terrorism and Political Violence 27(3):557-580.

Olson, Mancur. 1965. The logic of collective action: Public goods and the theory groups. Cambridge: Harvard University Press.

Ord, Keith. 1975. "Estimation methods for models of spatial interaction." Journal of the American Statistical Association 70(349):120-126.

Petersen, Roger D. 2002. Understanding Ethnic Violence: Fear, hatred, and resentment in twentieth century Eastern Europe. Cambridge: Cambridge University Press.

Petterson, Therése and Lotta Themnér. 2012. UCDP Actor Dataset Codebook. Version 2.12012. Department of Peace and Conflict Research, Uppsala University: Uppsala Conflict Data Program (UCDP).

Phillips, Brian J. 2014. "Terrorist group cooperation and longevity." International Studies Quarterly 58(2):336-347.

Poast, Paul. 2010. "(Mis) Using Dyadic Data to Analyze Multilateral Events." Political analysis 18(4):403-425. 
Quinn, Jason, Madhav Joshi and Erik Melander. 2019. "One Dyadic Peace Leads to Another? Conflict Systems, Terminations, and Net Reduction in Fighting Groups." International Studies Quarterly .

Quiroz Flores, Alejandro. 2008. "Copula functions and bivariate distributions for survival analysis: An application to government survival." NYU Department of Politics Working Paper.

Salehyan, Idean. 2007. "Transnational Rebels: Neighboring States as Sanctuary for Rebel Groups." World Politics 59(2):217-242.

Schnytzer, Adi. 1994. "An economic model of regime change: Freedom as a public good." Public Choice 79(3-4):325-339.

Siegel, David A. 2009. "Social Networks and Collective Action." American Journal of Political Science 53(1):122-138.

Simmons, Beth A. and Zachary Elkins. 2004. "The globalization of liberalization: Policy diffusion in the international political economy." American Political Science Review 98(1):171-189.

Stedman, Stephen John. 1997. "Spoiler problems in peace processes." International Security $22(2): 5-53$.

Steinwand, Martin C. 2011. "Estimating Free-Riding Behavior: The StratAM Model." Political Analysis 19(4):488-502.

Svolik, Milan. 2008. "Authoritarian reversals and democratic consolidation." American Political Science Review 102(02):153-168.

Thomas, Jakana. 2014. "Rewarding bad behavior: How governments respond to terrorism in civil war." American Journal of Political Science 58(4):804-818.

Walter, Barbara F. 1999. "Designing transitions from civil war: Demobilization, democratization, and commitments to peace." International Security 24(1):127-155.

Walter, Barbara F. 2004. "Does conflict beget conflict? Explaining recurring civil war." Journal of Peace Research 41(3):371-388. 
Walter, Barbara F. 2019. "Explaining the number of rebel groups in civil wars." International Interactions 45(1):1-27.

Ward, Michael D. and Kristian Skrede Gleditsch. 2002. "Location, location, location: An MCMC appraoch to modeling the spatial context of war and peace." Political Analysis 10(3):244-260.

Wood, Elisabeth Jean. 2003. Insurgent Collective Action and Civil War in El Salvador. Cambridge: Cambridge University Press.

Wood, Reed M and Jacob D Kathman. 2015. "Competing for the Crown Inter-rebel Competition and Civilian Targeting in Civil War." Political Research Quarterly 68(1):167-179.

Wucherpfennig, Julian, Nils W Metternich, Lars-Erik Cederman and Kristian Skrede Gleditsch. 2012. "Ethnicity, the state, and the duration of civil war." World Politics 64(1):79115. 


\section{Appendix: Maximum Likelihood Estimation}

We require to estimate the following model:

$$
y=\rho \mathbf{W} y+\mathbf{X} \beta+\frac{1}{\lambda} u
$$

where $y$ is the $\log$ of duration $y^{*}$, i.e. $y=\ln y^{*}$. As shown by Hays and Kachi (2015), in order to derive the likelihood via change of variables, we solve for $u$ :

$$
g^{-1}(y)=u=\lambda(y-\rho \mathbf{W} y-\mathbf{X} \beta)
$$

$$
u=y \lambda(\mathbf{I}-\rho \mathbf{W})-\lambda X \beta .
$$

The likelihood is thus given by

$$
L=|\operatorname{det}(\mathbf{J})| \times \prod_{i=1}^{n} f\left(u_{i}\right)
$$

where $\mathbf{J}$ is the Jacobian matrix of $g^{-1}(y)$.

Different parameterizations are now possible, depending on the analyst's choice for the distribution for $u$. Because the log-normal is similar to the widely known SAR for normally distributed errors for a logged dependent variable, we here focus on the Weibull parameterization. For a Weibull model, $u$ is distributed type-I-extreme-value:

$$
f(u)=e^{u} e^{-e^{u}}
$$

The likelihood function is then

$$
L=|\operatorname{det}(\mathbf{J})| e^{u} e^{-e^{u}},
$$

i.e.,

$$
L=|\operatorname{det}(\mathbf{J})| \times \exp [\lambda(y-\rho \mathbf{W} y-\mathbf{X} \beta)] \times \exp [-\exp (\lambda(y-\rho \mathbf{W} y-\mathbf{X} \beta)]
$$


with the corresponding log-likelihood function

$$
L L=\ln |\operatorname{det}(\mathbf{J})|+\lambda(y-\rho \mathbf{W} y-\mathbf{X} \beta)-\exp [\lambda(y-\rho \mathbf{W} y-\mathbf{X} \beta)]
$$

Using eq. 3 and insights from Ord (1975), the log-Jacobian term can calculated at the outset:

$$
\ln |\operatorname{det}(\mathbf{J})|=\sum_{i=1}^{n} \ln \left(1-\rho \omega_{j}\right)+\ln \lambda
$$

where $\omega_{j}, j=1, \ldots, n$ are eigenvalues of $\mathbf{W}$. 


\section{Appendix: Construction of W CONNECTIVITy Matrix}

We begin by stacking the vector of rank-ordered entering durations $W$ on top of the vector of fighting durations $y$ :

$$
\mathbf{Y}_{2 N \times 1}=\left[\begin{array}{c}
z_{1} \\
\vdots \\
z_{n} \\
y_{1} \\
\vdots \\
y_{n}
\end{array}\right]
$$

Since we do not have covariates (not even a constant) for $\mathbf{z}$, the resulting matrix form of our model looks as follows:

$$
\left[\begin{array}{l}
z \\
y
\end{array}\right]=\rho \mathbf{W} \times\left[\begin{array}{l}
z \\
y
\end{array}\right]+\left[\begin{array}{l}
X \\
X
\end{array}\right] \beta+\left[\begin{array}{l}
u \\
u
\end{array}\right]
$$

Next, we divide $\mathbf{W}$ into four component matrices:

$$
\left[\begin{array}{l}
z \\
y
\end{array}\right]=\rho\left[\begin{array}{ll}
0 & 0 \\
L & R
\end{array}\right] \times\left[\begin{array}{l}
z \\
y
\end{array}\right]+\left[\begin{array}{l}
X \\
X
\end{array}\right] \beta+\left[\begin{array}{l}
u \\
u
\end{array}\right.
$$

The upper left and upper right quadrant of the $\mathbf{W}$ matrix are filled with zeros. By matrix algebra, the waiting durations therefore merely make their way into the model through the endogenous spatial lag, such that the dependent variable on the left-hand side are solely logged fighting durations. In $\mathbf{W}$, the lower left and lower right quadrant are defined according to our theoretical approach. Indeed, they transform Equation 12 into matrix form. In detail, the lower left quadrant $L$ captures the relationship between the fighting times and conflict entry times of rebel organizations, while the lower right quadrant reflects the interdependence between fighting times. Both $L$ and $R$ are block-diagonal by conflicts $\psi \in\{1, \ldots, \Psi\}$, 
meaning that we have $L_{\psi} \in\{1, \ldots, \Psi\}$ blocks within $L$ that correspond to each individual conflict in the data set.

$$
L=\left[\begin{array}{cccc}
L_{1} & 0 & \cdots & 0 \\
0 & L_{2} & \ddots & \vdots \\
\vdots & \ddots & \ddots & 0 \\
0 & \cdots & 0 & L_{\Psi}
\end{array}\right]
$$

Every block on the diagonal describes the suggested relationship between the conflict entry times and fighting times. Here $n_{z}$ indexes the $n$ rebel organizations active in conflict $\psi$.

$$
L_{\psi}=\left[\begin{array}{cccc}
0 & 0 & \cdots & 0 \\
1 & -1 & \ddots & \vdots \\
\vdots & \ddots & \ddots & 0 \\
1 & \cdots & 1 & -\left(n_{\psi}-1\right)
\end{array}\right]
$$

Having explored the lower left quadrant of the $M$ matrix, we now turn to the lower right quadrant. $R$ is again block diagonal by conflict $\psi$.

$$
R=\left[\begin{array}{cccc}
R_{1} & 0 & \cdots & 0 \\
0 & R_{2} & \ddots & \vdots \\
\vdots & \ddots & \ddots & 0 \\
0 & \cdots & 0 & R_{\Psi}
\end{array}\right]
$$

Since Equation 12 involves on the right hand side all fighting durations of all other rebel organizations, merely the diagonal is zero.

$$
R_{\psi}=\left[\begin{array}{cccc}
0 & 1 & \cdots & 1 \\
1 & \ddots & \ddots & \vdots \\
\vdots & \ddots & \ddots & 1 \\
1 & \cdots & 1 & 0
\end{array}\right]
$$


Finally, the simultaneous equations setup to accommodate different entry timings requires us to perform transformations (via the connectivity matrix), on the raw durations, but the accelerated failure time form of the event history model is written in log time. Thus, we create the final connectivity matrix $\mathbf{W}=\mathbf{M W}^{*}$, where $y^{*}$ are the raw (unlogged) durations and $\mathbf{W}^{*}$ denotes the "raw" connectivities based on the setup given above, such that

$$
\ln \left(\mathbf{W}^{*} y\right)=\mathbf{M} \mathbf{W}^{*} \ln \left(y^{*}\right)=\mathbf{W} y
$$

Thus, we solve for $\mathbf{M}$, which is a diagonal matrix for which the elements on the diagonal are given by $\frac{\ln \left(\mathbf{W}^{*} y^{*}\right)}{\mathbf{W}^{*} \ln \left(y^{*}\right)}$ (element-wise division). Note that largest eigenvalue needs to be less than $\frac{1}{\rho}$ to be well defined, which is the case in our empirical applications. See page 920 and especially footnote 40 in Bramoullé, Kranton and D'Amours (2014) that outlines conditions for unique interior equilibria. 


\section{APPENDIX: TABLES}

TABLE B1. Likelihoods for different spatial duration estimators

\begin{tabular}{l|c|c|c|c|c|} 
Distribution & pdf & Naive Log-likelihood & Spatial Log-Likelihood & $\begin{array}{c}\text { Naive Expected Duration } \\
\mu=E[\exp (y)]\end{array}$ & $\begin{array}{c}\text { Spatial Expected Duration } \\
\mu=E[\exp (y)]\end{array}$ \\
\hline Weibull & $f(u)$ & $u=\frac{1}{\sigma}(y-X \beta)$ & $u=\frac{1}{\sigma}(y-p W y-X \beta)$ & $e^{X \beta} \Gamma(1+\sigma)$ & $e^{(I-\rho W)^{-1} X \beta} \Gamma(1+\sigma)$ \\
\hline Log-logistic & $e^{u} e^{-e^{u}}$ & $u-e^{u}-\sigma$ & $u-e^{u}-\sigma+\ln \left(1-\rho \omega_{i}\right)$ & $\frac{e^{X \beta} \pi \sigma}{\sin (\pi \sigma)}$ for $\sigma<1$ & $\frac{e^{(I-X \beta)^{-1}(X \beta)} \pi \sigma}{\sin (\pi \sigma)}$ for $\sigma<1$ \\
\hline Log-Normal & $\left(2 \pi \sigma^{2}\right)^{-\frac{1}{2}} e^{-\frac{1}{2} u^{2}}$ & $-\frac{1}{2}\left(\ln (2 \pi)+\sigma^{2}+u^{\prime} u\right)$ & $-\frac{1}{2}\left(\ln (2 \pi)+\sigma^{2}+u^{\prime} u\right)+\ln \left(1-\rho \omega_{i}\right)$ & $e^{X \beta+\frac{1}{2} \sigma}$ & $e^{\left[(I-\rho W)^{-1} X \beta+\frac{1}{2} \sigma^{2}\right]}$ \\
\hline
\end{tabular}


TABLE B2. Summary statistics for outcome and explanatory variables

\begin{tabular}{lccccc}
\hline & N & Mean & St. Dev. & Min & Max \\
\hline Fighting Duration & 379 & 1,300 & 2,047 & 1 & 16 \\
Time until Entry & 379 & 3,817 & 4,794 & 1 & 22 \\
Splinter & 379 & 0.129 & 0.336 & 0 & 1 \\
Alliance & 379 & 0.090 & 0.286 & 0 & 1 \\
Previous Victory & 379 & 0.541 & 1.044 & 0 & 5 \\
Previous Agreement & 379 & 0.288 & 0.940 & 0 & 7 \\
Legal Political Wing & 379 & 0.182 & 0.386 & 0 & 1 \\
Rebel Strength & 379 & 1.802 & 0.836 & 1 & 5 \\
Secession & 379 & 0.282 & 0.451 & 0 & 1 \\
Veto & 379 & 0.380 & 0.653 & 0 & 3 \\
Order & 379 & 3.164 & 4.104 & 1 & 25 \\
\hline
\end{tabular}


TABLE B3. Estimates for k-dyadic secession and non-seccession models. Weibull duration models in accelerated failure time format. Standard errors are provided in parenthesis. Outcome variable is the fighting duration of rebel organizations measured in days.

\begin{tabular}{lcc}
\hline & K-dyadic Secession Model & K-dyadic Non-Secession Model \\
\hline Intercept & $6.76^{* * *}$ & $6.28^{* * *}$ \\
Time until Entry ${ }_{l o g}$ & $(0.93)$ & $(0.39)$ \\
& -0.05 & 0.02 \\
Splinter & $(0.04)$ & $(0.03)$ \\
& 0.20 & 0.02 \\
Alliance & $(0.38)$ & $(0.32)$ \\
& 0.01 & -0.38 \\
Previous.Victory & $(0.59)$ & $(0.36)$ \\
& 0.40 & $1.08^{* * *}$ \\
Previous.Agreement & $(0.56)$ & $(0.26)$ \\
& 0.67 & 0.14 \\
Legal.Political.Wing & $(0.50)$ & $(0.20)$ \\
& $-0.94^{* *}$ & -0.40 \\
Rebel.Strength & $(0.36)$ & $(0.28)$ \\
& 0.26 & 0.08 \\
Veto & $(0.36)$ & $(0.17)$ \\
& 0.02 & 0.23 \\
Order & $(0.30)$ & $(0.17)$ \\
& -0.07 & $-0.23^{* * *}$ \\
Country dummies & $(0.08)$ & $(0.08)$ \\
Scale ${ }_{l o g}$ & $y e s$ & $0.31^{* * *}$ \\
\hline Log-Likelihood & $0.15^{*}$ & $(0.05)$ \\
$\mathrm{N}$ & $(0.08)$ & -525.27 \\
AIC & -186.02 & 272 \\
BIC & 107 & 1174.53 \\
\hline$* * * p<0.01,{ }^{* *} p<0.05,{ }^{*} p<0.1$ & 428.05 & 1398.09 \\
\hline & 502.88 &
\end{tabular}


TABLE B4. Estimates for log-logistic and log-normal spatial models using the main model specifications. Duration models in accelerated failure time format. Standard errors are provided in parenthesis. Outcome variable is the fighting duration of rebel organizations measured in days.

\begin{tabular}{|c|c|c|c|c|c|c|}
\hline & Spatial Veto & Secession & Non-Secession & Spatial Veto & Secession & Non-Secession \\
\hline \multirow[t]{2}{*}{ Intercept } & $4.51^{* * *}$ & $5.18^{* * *}$ & $4.57^{* * *}$ & $4.40^{* * *}$ & $7.83^{* * *}$ & $4.69^{* * *}$ \\
\hline & $(0.44)$ & $(1.29)$ & $(0.46)$ & $(0.38)$ & $(1.22)$ & $(0.47)$ \\
\hline \multirow[t]{2}{*}{ Time until Entry ${ }_{l o g}$} & -0.01 & -0.05 & 0.06 & -0.01 & -0.09 & $0.07^{*}$ \\
\hline & $(0.03)$ & $(0.05)$ & $(0.04)$ & $(0.03)$ & $(0.06)$ & $(0.04)$ \\
\hline \multirow[t]{2}{*}{ Splinter } & -0.23 & -0.47 & -0.17 & -0.23 & -0.03 & -0.13 \\
\hline & $(0.29)$ & $(0.43)$ & $(0.35)$ & $(0.32)$ & $(0.52)$ & $(0.39)$ \\
\hline \multirow[t]{2}{*}{ Alliance } & -0.05 & 0.20 & -0.16 & 0.03 & 0.13 & -0.31 \\
\hline & $(0.34)$ & $(0.57)$ & $(0.40)$ & $(0.39)$ & $(0.85)$ & $(0.47)$ \\
\hline \multirow[t]{2}{*}{ Previous Victory } & $0.99^{* * *}$ & 0.77 & $1.19^{* * * *}$ & $1.13^{* * * *}$ & $1.57^{* *}$ & $0.96^{* * * *}$ \\
\hline & $(0.23)$ & $(0.59)$ & $(0.36)$ & $(0.23)$ & $(0.78)$ & $(0.32)$ \\
\hline \multirow[t]{2}{*}{ Previous Agreement } & 0.08 & $1.05^{* *}$ & 0.20 & 0.06 & -0.11 & 0.19 \\
\hline & $(0.17)$ & $(0.52)$ & $(0.20)$ & $(0.19)$ & $(0.61)$ & $(0.24)$ \\
\hline \multirow[t]{2}{*}{ Legal Political Wing } & $-0.82^{* * *}$ & $-1.04^{* *}$ & -0.54 & $-0.93^{* * *}$ & $-1.23^{* * *}$ & -0.57 \\
\hline & $(0.27)$ & $(0.42)$ & $(0.34)$ & $(0.27)$ & $(0.43)$ & $(0.36)$ \\
\hline \multirow[t]{2}{*}{ Rebel Strength } & 0.07 & 0.43 & -0.09 & 0.04 & $-0.56^{*}$ & -0.19 \\
\hline & $(0.16)$ & $(0.40)$ & $(0.21)$ & $(0.16)$ & $(0.34)$ & $(0.18)$ \\
\hline \multirow[t]{2}{*}{ Veto } & -0.25 & -0.32 & 0.02 & -0.15 & -0.13 & 0.13 \\
\hline & $(0.18)$ & $(0.32)$ & $(0.21)$ & $(0.20)$ & $(0.41)$ & $(0.23)$ \\
\hline \multirow[t]{2}{*}{ Order } & $-0.15^{* *}$ & -0.03 & $-0.25^{* *}$ & $-0.16^{* *}$ & 0.12 & $-0.21^{* *}$ \\
\hline & $(0.07)$ & $(0.09)$ & $(0.10)$ & $(0.07)$ & $(0.11)$ & $(0.10)$ \\
\hline \multirow[t]{2}{*}{ Secession } & $0.55^{* *}$ & & & $0.75^{* * *}$ & & \\
\hline & $(0.26)$ & & & $(0.28)$ & & \\
\hline Country dummies & yes & yes & yes & yes & yes & yes \\
\hline \multirow[t]{2}{*}{$\rho$} & $0.14^{* * *}$ & $0.09^{*}$ & $0.09^{* *}$ & $0.15^{* * *}$ & 0.10 & $0.10^{* *}$ \\
\hline & $(0.04)$ & $(0.05)$ & $(0.04)$ & $(0.04)$ & $(0.07)$ & $(0.04)$ \\
\hline \multirow[t]{2}{*}{ Scale $_{l o g}$} & $-0.08^{*}$ & $-0.25^{* * *}$ & -0.06 & $0.55^{* * *}$ & $0.53^{* * *}$ & $0.61^{* * *}$ \\
\hline & $(0.04)$ & $(0.08)$ & $(0.05)$ & $(0.04)$ & $(0.07)$ & $(0.04)$ \\
\hline Log-Likelihood & -738.55 & -188.82 & -534.25 & -747.86 & -208.86 & -552.55 \\
\hline $\mathrm{N}$ & 379 & 107 & 272 & 379 & 107 & 272 \\
\hline AIC & 1623.10 & 435.64 & 1194.50 & 1641.72 & 451.71 & 1215.10 \\
\hline $\mathrm{BIC}$ & 1910.54 & 513.15 & 1421.67 & 1929.16 & 497.15 & 1413.42 \\
\hline
\end{tabular}


TABLE B5. Estimates for the main fighting duration model with outcome variables in accelerated failure time format. Standard errors are provided in parenthesis. Outcome variable is the fighting duration of rebel organizations measured in days.

\begin{tabular}{|c|c|}
\hline & Spatial Veto Model controlling for outcomes \\
\hline \multirow[t]{2}{*}{ Intercept } & $6.53^{* * *}$ \\
\hline & $(0.34)$ \\
\hline \multirow{2}{*}{ Time until Entry ${ }_{l o g}$} & -0.04 \\
\hline & $(0.02)$ \\
\hline \multirow{2}{*}{ Splinter } & 0.01 \\
\hline & $(0.24)$ \\
\hline \multirow[t]{2}{*}{ Alliance } & $-0.64^{* *}$ \\
\hline & $(0.29)$ \\
\hline \multirow{2}{*}{ Previous Victory } & $0.50^{* * *}$ \\
\hline & $(0.19)$ \\
\hline \multirow[t]{2}{*}{ Previous Agreement } & 0.05 \\
\hline & $(0.15)$ \\
\hline \multirow[t]{2}{*}{ Legal Political Wing } & $-0.55^{* *}$ \\
\hline & $(0.22)$ \\
\hline \multirow{2}{*}{ Rebel Strength } & 0.12 \\
\hline & $(0.14)$ \\
\hline \multirow[t]{2}{*}{ Veto } & -0.01 \\
\hline & $(0.15)$ \\
\hline \multirow[t]{2}{*}{ Order } & $-0.10^{*}$ \\
\hline & $(0.06)$ \\
\hline \multirow[t]{2}{*}{ Secession } & 0.17 \\
\hline & $(0.23)$ \\
\hline \multirow[t]{2}{*}{ Government Victory } & $-1.42^{* * *}$ \\
\hline & $(0.24)$ \\
\hline \multirow{2}{*}{ Rebel Victory } & $-0.92^{* *}$ \\
\hline & $(0.36)$ \\
\hline \multirow{2}{*}{ Agreement } & 0.28 \\
\hline & $(0.25)$ \\
\hline Country dummies & yes \\
\hline \multirow[t]{2}{*}{$\rho$} & $0.10^{* * *}$ \\
\hline & $(0.03)$ \\
\hline \multirow{2}{*}{ Scale $_{l o g}$} & $0.24^{* * *}$ \\
\hline & $(0.04)$ \\
\hline Log-Likelihood & -699.26 \\
\hline $\mathrm{N}$ & 379 \\
\hline $\mathrm{AIC}$ & 1550.51 \\
\hline $\mathrm{BIC}$ & 1849.76 \\
\hline
\end{tabular}


TABLE B6. Spatial duration models spatial impact only on strong and weak rebel organizations respectively. Estimates for fighting duration model in accelerated failure time format. Standard errors are provided in parenthesis. Outcome variable is the fighting duration of rebel organizations measured in days.

\begin{tabular}{|c|c|c|}
\hline & Strong rebel organizations & Weak rebel organizations \\
\hline \multirow[t]{2}{*}{ Intercept } & $6.09^{* * *}$ & $5.93^{* * *}$ \\
\hline & $(0.34)$ & $(0.36)$ \\
\hline \multirow[t]{2}{*}{ Time until Entry ${ }_{l o g}$} & -0.02 & -0.02 \\
\hline & $(0.03)$ & $(0.03)$ \\
\hline \multirow[t]{2}{*}{ Splinter } & 0.02 & 0.01 \\
\hline & $(0.26)$ & $(0.26)$ \\
\hline \multirow[t]{2}{*}{ Alliance } & -0.36 & $-0.55^{*}$ \\
\hline & $(0.30)$ & $(0.30)$ \\
\hline \multirow[t]{2}{*}{ Previous Victory } & $0.83^{* * *}$ & $0.77^{* * *}$ \\
\hline & $(0.22)$ & $(0.23)$ \\
\hline \multirow[t]{2}{*}{ Previous Agreement } & 0.05 & 0.05 \\
\hline & $(0.16)$ & $(0.16)$ \\
\hline \multirow[t]{2}{*}{ Legal Political Wing } & $-0.57^{* * *}$ & $-0.58^{* * *}$ \\
\hline & $(0.22)$ & $(0.22)$ \\
\hline \multirow{2}{*}{ Rebel Strength } & 0.16 & 0.24 \\
\hline & $(0.15)$ & $(0.15)$ \\
\hline \multirow[t]{2}{*}{ Veto } & 0.17 & -0.04 \\
\hline & $(0.14)$ & $(0.15)$ \\
\hline \multirow[t]{2}{*}{ Order } & $-0.14^{* *}$ & $-0.14^{* *}$ \\
\hline & $(0.06)$ & $(0.06)$ \\
\hline \multirow[t]{2}{*}{ Secession } & $0.54^{* *}$ & $0.53^{* *}$ \\
\hline & $(0.24)$ & $(0.24)$ \\
\hline Country dummies & yes & yes \\
\hline \multirow[t]{2}{*}{5} & 0.03 & $0.10^{* * *}$ \\
\hline & $(0.09)$ & $(0.03)$ \\
\hline \multirow[t]{2}{*}{ Scale $_{l o g}$} & $0.30^{* * *}$ & $0.29^{* * *}$ \\
\hline & $(0.04)$ & $(0.04)$ \\
\hline Log-Likelihood & -725.06 & -720.21 \\
\hline $\mathrm{N}$ & 379 & 379 \\
\hline $\mathrm{AIC}$ & 1596.13 & 1586.41 \\
\hline $\mathrm{BIC}$ & 1883.57 & 1873.85 \\
\hline
\end{tabular}


TABLE B7. Estimates for main models including only rebel organizations nested in multi-actor conflicts. Weibull duration models in accelerated failure time format. Standard errors are provided in parenthesis. Outcome variable is the fighting duration of rebel organizations measured in days.

\begin{tabular}{|c|c|c|c|}
\hline & Veto Model & Spatial Model & Spatial Veto Model \\
\hline \multirow[t]{2}{*}{ Intercept } & $4.21^{* * *}$ & $4.25^{* * *}$ & $4.24^{* * *}$ \\
\hline & $(0.36)$ & $(0.36)$ & $(0.34)$ \\
\hline \multirow{2}{*}{ Time until Entry ${ }_{l o g}$} & -0.03 & -0.03 & -0.03 \\
\hline & $(0.03)$ & $(0.03)$ & $(0.03)$ \\
\hline \multirow[t]{2}{*}{ Splinter } & 0.32 & 0.27 & 0.28 \\
\hline & $(0.24)$ & $(0.24)$ & $(0.25)$ \\
\hline \multirow[t]{2}{*}{ Alliance } & -0.39 & $-0.52^{* *}$ & $-0.51^{*}$ \\
\hline & $(0.26)$ & $(0.26)$ & $(0.26)$ \\
\hline \multirow[t]{2}{*}{ Previous Victory } & $1.03^{* * *}$ & $0.95^{* * *}$ & $0.95^{* * *}$ \\
\hline & $(0.20)$ & $(0.20)$ & $(0.20)$ \\
\hline \multirow{2}{*}{ Previous Agreement } & 0.06 & 0.08 & 0.07 \\
\hline & $(0.15)$ & $(0.14)$ & $(0.14)$ \\
\hline \multirow[t]{2}{*}{ Legal Political Wing } & -0.17 & -0.14 & -0.13 \\
\hline & $(0.26)$ & $(0.26)$ & $(0.26)$ \\
\hline \multirow[t]{2}{*}{ Rebel Strength } & 0.20 & 0.24 & 0.24 \\
\hline & $(0.16)$ & $(0.16)$ & $(0.16)$ \\
\hline \multirow[t]{2}{*}{ Veto } & 0.10 & & -0.03 \\
\hline & $(0.13)$ & & $(0.14)$ \\
\hline \multirow[t]{2}{*}{ Order } & $-0.18^{* * *}$ & $-0.17^{* * *}$ & $-0.17^{* * *}$ \\
\hline & $(0.05)$ & $(0.05)$ & $(0.05)$ \\
\hline \multirow[t]{2}{*}{ Secession } & $0.78^{* *}$ & $0.77^{* *}$ & $0.76^{* *}$ \\
\hline & $(0.32)$ & $(0.30)$ & $(0.31)$ \\
\hline Country dummies & yes & yes & yes \\
\hline \multirow[t]{2}{*}{ Scale $_{l o g}$} & $0.14^{* * *}$ & $0.12^{* *}$ & $0.12^{* *}$ \\
\hline & $(0.05)$ & $(0.05)$ & $(0.05)$ \\
\hline \multirow[t]{2}{*}{$\rho$} & & $0.08^{* * *}$ & $0.08^{* * *}$ \\
\hline & & $(0.03)$ & $(0.03)$ \\
\hline Log-Likelihood & -459.58 & -455.92 & -455.89 \\
\hline $\mathrm{N}$ & 260 & 260 & 260 \\
\hline $\mathrm{AIC}$ & 1035.16 & 1027.83 & 1029.79 \\
\hline $\mathrm{BIC}$ & 1241.68 & 1234.35 & 1239.87 \\
\hline
\end{tabular}




\section{Appendix: Figures}

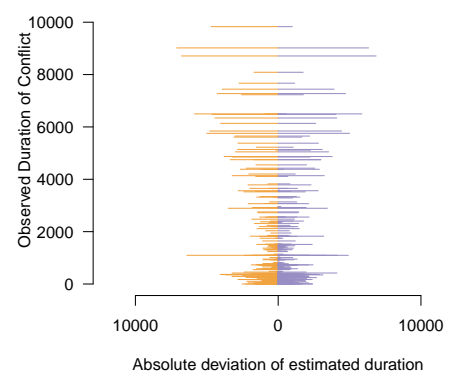

(a) Absolute deviation

Figure C1. Model fit assessment comparing absolute deviation from the observed durations for Model 1 (non-strategic Weibull controlling for the number of rebel organizations) and Model 3 (spatial strategic Weibull including the number of rebel organizations). In all panels orange refers to Model 1, while purple pertains to Model 3.

Nils W. Metternich: Department of Political Science

Current address: University College London, London, WC1H 9QU, UK

Email address: n.metternich@ucl.ac.uk

Julian Wucherpfennig: Centre for International Security

Current address: Hertie School, Berlin, Germany

Email address: wucherpfennig@hertie-school.org 